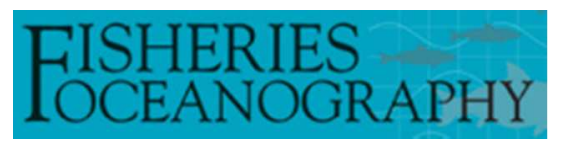

\title{
Spatial distribution of Greenland halibut Reinhardtius hippoglossoides in relation to abundance and hypoxia in the Estuary and Gulf of St. Lawrence
}

\begin{tabular}{|r|l|}
\hline Journal: & Fisheries Oceanography \\
\hline Manuscript ID: & FOG-12-0954.R1 \\
\hline Manuscript Type: & Original Article \\
\hline Date Submitted by the Author: & n/a \\
\hline Complete List of Authors: & $\begin{array}{l}\text { Ait Youcef, Wahiba; Université du Québec à Rimouski, Institut des sciences } \\
\text { de la mer de Rimouski } \\
\text { Lambert, Yvan; Institut Maurice-Lamontagne, Pêches et Océans Canada } \\
\text { Audet, Céline; Université du Québec à Rimouski, Institut des sciences de la } \\
\text { mer de Rimouski }\end{array}$ \\
\hline Keywords: & $\begin{array}{l}\text { demersal < habitat, hypoxia < oceanography, dispersal < biological } \\
\text { processes, density dependent < biological dynamics, habitat < ecology, } \\
\text { generalized additive model < statistics, Atlantic < region }\end{array}$ \\
\hline \multicolumn{2}{|l}{} \\
\hline
\end{tabular}


1 Spatial distribution of Greenland halibut Reinhardtius hippoglossoides in

2 relation to abundance and hypoxia in the Estuary and Gulf of St.

\section{Lawrence}

\section{WAHIBA AIT YOUCEF ${ }^{1,}$ YVAN LAMBERT $^{2, \dagger}$ AND CÉLINE AUDET $^{1}$}

$5 \quad{ }^{1}$ Institut des sciences de la mer de Rimouski, Université du Québec à Rimouski, 310 Allée

6 des Ursulines, Rimouski, Québec, G5L 3A1, Canada

$7{ }^{2}$ Pêches et Océans Canada, Institut Maurice-Lamontagne, 850 route de la Mer, Mont-Joli, 8 Québec, G5H 3Z4, Canada

$9 \quad{ }^{\dagger}$ Corresponding author: yvan.lambert@dfo-mpo.gc.ca 


\section{ABSTRACT}

12 Annual bottom-trawl surveys (1990-2010) were used to examine associations between

13 environmental conditions, spatial distribution, and size-specific abundance of Greenland

14 halibut Reinhardtius hippoglossoides in the estuary and Gulf of St. Lawrence (EGSL), and

15 to test the influence of hypoxic conditions on habitat selection. Size classes representing

16 juvenile, immature and adult fish were used for the analyses. The highest concentrations of

17 fish were found in the St. Lawrence estuary at both high and low levels of stock abundance.

18 The areas occupied by $50 \%, 75 \%$, and $95 \%$ of juvenile fish expanded with higher

19 population abundance. However, contrary to our predictions, densities in marginal habitats

20 did not increase at a higher rate than in optimal habitats. Fish longer than $32 \mathrm{~cm}$ were

21 distributed over a broader area than juvenile fish. Their abundance explained a limited

22 proportion of the variability in spatial distribution. The spatial dynamics of Greenland

23 halibut in the EGSL is best described by a proportional density model where the rate of

24 increase in local density is associated with population abundance. Habitats selected by

25 Greenland halibut were characterized by low dissolved oxygen (DO) levels. The strong

26 association between high fish densities and low DO concentrations indicates a high

27 tolerance of Greenland halibut to hypoxia. It also indicates that negative effects, if present,

28 could be compensated by other factors like food availability and/or refuge from predation.

29 The results of this study also clearly define the St. Lawrence estuary as the major nursery 30 area for the EGSL population.

31 Key words: hypoxia, density dependent, habitat selection, spatial distribution, Greenland 
32 halibut, Estuary and Gulf of St. Lawrence

33

1

2

3

4
5

6

7

8

9

10

11

12

13

14

15

16

17

18

19

20

21

22

23

24

25

26

27

28

29

30

31

32

33

34

35

36

37

38

39

40

41

42

43

44

45

46

47

48

49

50

51

52

53

54

55

56

57

58

59

60 


\section{INTRODUCTION}

35 Understanding patterns in the spatial distribution of marine fish populations in relation to 36 habitat availability is an important consideration in the management of exploited resources 37 (Kruse et al., 2001). The distribution and abundance of marine species in relation to 38 environmental variables have been the subjects of many ecological studies; it has been 39 suggested that the relationship between geographic distribution and population abundance 40 is the result of density-dependent habitat selection (MacCall, 1990). Based on the ideal free 41 distribution (IFD) theory, if individuals have a perfect knowledge of their environment and 42 are free to move among available habitats, they will select habitats maximizing their fitness 43 (Fretwell and Lucas, 1970): during periods of low abundance, only the best habitats should 44 be occupied, while individuals would occupy less optimal habitats as abundance increases.

45 In conditions of high abundance, the best habitats based on abiotic factors would be less 46 attractive and profitable due to increased intraspecific competition for food and space.

47 Density-dependent spatial distributions have been described for a variety of pelagic 48 species such as California sardine Sardinops sagax caerulea (MacCall, 1976), northern 49 anchovy Engraulis mordax (Radovich, 1976), Peruvian anchovy Engraulis ringens (Csirke, 50 1980), Atlantic menhaden Brevoortia tyrannus (Schaaf, 1980), Atlantic herring Clupea 51 harengus (Winters and Wheeler, 1985), and longfin squid Loligos pealei (Lange, 1991).

52 For demersal species, evidence for density-dependent spatial distributions is less conclusive 53 (Craig et al., 2005). Positive correlations between abundance and occupied area have been 54 reported for Atlantic cod Gadus morhua (Rose and Leggett, 1991; Swain and Wade, 1993; 55 Swain and Sinclair, 1994; Atkinson et al., 1997), and haddock Melanogrammus aeglefinus 56 (Crecco and Overholtz, 1990; Marshall and Frank, 1995). However, other studies on 
57 various populations of silver hake, Merluccius bilinearis, haddock, Melanogrammus 58 aeglefinus, pollock, Pollachius virens, red hake, Urophycis chuss, yellowtail flounder, 59 Limanda ferruginea, winter flounder, Pseudopleuronectes americanus, American plaice 60 Hippoglossoides platessoides, Atlantic cod and a Clupeoidea, Sardinella sp. did not 61 provide support for density-dependent habitat selection (Murawski and Finn, 1988, Swain 62 and Morin, 1996, Schneider et al., 1997, Petitgas, 1998).

63 Habitat selection by marine fishes depends on a variety of biotic factors, such as 64 prey and predator abundances, and on abiotic factors (Swain et al., 1998, Swain and Benoît, 65 2006). Depth, water temperature, salinity, and dissolved oxygen (DO) are among the 66 common physical factors that have been related to the distribution of demersal fish 67 (D’Amours, 1993, Castonguay et al., 1999, Mueter and Norcross, 1999, Neuenfeldt and 68 Beyer, 2003, Cote et al., 2004, Craig et al., 2005, Swain and Benoît, 2006).

69 Greenland halibut (Reinhardtius hippoglossoides) is widely distributed in the 70 estuary and Gulf of St. Lawrence (EGSL). It constitutes a significant component of the 71 groundfish fishery resource in this region (Bowering, 1982), with a mean annual catch $(\sim$ $723500 \mathrm{t})$ representing about $52 \%$ of the total biomass of fish catches in recent years (2005 73 2010). Greenland halibut is generally found in the channels of the EGSL at depths ranging 74 between 130 and $500 \mathrm{~m}$. These bottom waters are characterized by relatively stable water 75 temperature $\left(4\right.$ to $\left.6^{\circ} \mathrm{C}\right)$ and salinity $(\sim 34)$ conditions and low concentrations of DO. 76 Between 1930 and the mid-1980's, oxygen concentrations in the bottom waters of the lower 77 St. Lawrence estuary decreased by $48 \%$, i.e., from $125 \mu \mathrm{mol} \mathrm{L} \mathrm{L}^{-1}$ (37.7\% saturation) to an 78 average of $65 \mu \mathrm{mol} \mathrm{L} \mathrm{L}^{-1}(20.7 \%$ saturation) (Gilbert et al., 2005). The current DO 79 concentrations in the estuary are close to levels that have caused either significant 
80 mortalities or changes in migration patterns, trophic relationships, community structure,

81 productivity, or biodiversity in other ecosystems (Diaz and Rosenberg, 1995; Wu, 2002).

82 Despite the importance of this phenomenon in the St. Lawrence ecosystem, its effect has

83 only been studied on one fish species, Atlantic cod, which was shown to be sensitive to

84 hypoxia (D'Amours, 1993; Chabot, 2004). Greenland halibut appears to be more tolerant to

85 hypoxia than cod given its presence and its high abundance in deep waters reported to have

86 low DO levels. However, the impact of hypoxia on habitat selection by Greenland halibut

87 has never been assessed. Furthermore, no detailed analysis of the distribution of this species

88 in relation to fish density, development stage and/or environmental conditions has been

89 conducted in our area of interest (i.e. the EGSL).

90 The aims of the present study were 1) to describe associations among fish

91 distribution, fish density, and physical characteristics considered to be important in the

92 EGSL (spatial location, depth, temperature, and DO) in relation to fish size; 2) to assess

93 the importance of DO in habitat selection by Greenland halibut; 3) to determine whether

94 Greenland halibut distribution in this area follows ideal free distribution (IFD) theory.

95 Generalized Additive Model (GAM) techniques were used to study the effects of

96 environmental variables on fish distribution. To assess whether the IFD theory may apply

97 to Greenland halibut distribution, we examined relationships between abundance and

98 spatial distribution of both juvenile and adult fish in periods of low and high abundance.

99 


\section{MATERIALS AND METHODS}

101 Data collection

102 Data used in the present study were obtained from the summer multidisciplinary bottom103 trawl surveys conducted annually from 1990-2010 by Fisheries and Oceans, Canada (DFO) 104 and yearly sentinel fishery surveys conducted in collaboration with the industry from 1995 105 to 2010. These surveys use a stratified random sampling strategy with predetermined strata 106 based on geographic region and depth. The number of stations sampled per stratum is 107 proportional to the surface area, with a minimum of three stations per stratum for the 108 smaller strata (Bourdages et al., 2008, 2010). Between 163 and 238 fishing stations were 109 sampled each year over 32 strata in the DFO survey. From 1990 to 2003, the DFO surveys 110 were conducted on board the RV "Alfred Needler" using a URI bottom trawl with a $19 \mathrm{~mm}$

111 liner in the codend (24 min tows). Since 2004, surveys have been conducted on the RV 112 "Teleost", which is equipped with a Campelen 1800 trawl with $13 \mathrm{~mm}$ liner (15 min tows). 113 The URI trawl data was converted to Campelen trawl data based on comparative fishing 114 experiments held in 2004 and 2005 (Bourdages et al., 2007). Between 261 and 311 fishing 115 stations were sampled each year in the sentinel fishery survey. This survey, conducted by 116 nine otter trawlers does not cover the St. Lawrence estuary (i.e. 4 strata).

117 During the DFO surveys, conductivity, temperature, and depth (CTD) profiles were 118 obtained at each trawl station, allowing measurements of temperature, salinity, and water 119 density. Since 2004, CTD profilers have been equipped with Sea-Bird SBE43 oxygen 120 sensors to measure DO levels at each sampling station. An Aanderaa 3930 oxygen optode / 121 temperature sensor was also attached to the trawl from 2006 to 2010 . Only temperature data 122 were collected for each trawl station in the sentinel fishery surveys. 
123 Greenland halibut caught in each tow were measured until a maximal sample of 175

124 fish per tow was analyzed. Sex and sexual maturity of each fish were noted.

125 Analyses

126 To determine whether the distribution of Greenland halibut was heterogeneous according to 127 fish size, we examined variations in abundance and spatial distribution and relationships

128 with abiotic factors for juveniles and adults, males and females, grouped in different size

129 classes. Four size classes were used for the analyses: $13-22 \mathrm{~cm}, 23-31 \mathrm{~cm}, 32-43 \mathrm{~cm}$, and

$130 \geq 44 \mathrm{~cm}$. The first two size classes are largely represented by juvenile fish classified as one-

131 and two-years-old, respectively, with no distinction between sexes, and are grouped as one

132 size class, $15-31 \mathrm{~cm}$, for the analyses. In the absence of age determination, peaks in size

133 frequency distributions and distinct hiatus in the frequencies were used to determine the

134 size ranges and to classify fish as age 1 or 2 (Morin and Bernier 2003, DFO, 2011). The

$135 \quad 32-43 \mathrm{~cm}$ size class was largely represented by mature males while most females in the

136 same size class were immature. The largest size class included a high proportion of mature

137 females; few males reached lengths $\geq 44 \mathrm{~cm}$ (DFO, 2006, 2010, 2011).

138 Abundance

139 Stratified mean catch per standard tow $\bar{Y}_{t}$ in both surveys was used as an index of 140 Greenland halibut abundance (Smith, 1990):

$\bar{Y}_{t}=\sum_{h=1}^{K} \frac{\mathrm{A}_{h}}{\mathrm{~A}_{\mathrm{T}}} \bar{y}_{h t}$

142 where $\mathrm{A}_{h}$ is the area of stratum $h, \mathrm{~A}_{\mathrm{T}}$ is the total area surveyed, $K$ is the number of strata, 143 and $\bar{y}_{h t}$ is the mean catch rate of Greenland halibut of a particular size class in stratum $h$ 
144 and year $t$. The spatial distribution of Greenland halibut abundance was mapped using the 145 ACON data visualization software (http://www.mar.dfo-mpo.gc.ca/science/acon; last 146 accessed 13 November 2007). Interpolation between data points to draw contours was done 147 using Delaunay triangles. The logarithm of catch numbers per standard tow from the DFO 148 surveys were used to represent changes in spatial distribution for each size class. Spatial 149 distribution was mapped for periods of low and high abundance of Greenland halibut that 150 were determined using blocks of successive years represented by distinct levels of 151 population abundance.

152 Geographic range

153 Density-dependent spatial distributions of Greenland halibut were examined using methods 154 presented in Swain and Sinclair (1994), Marshall and Frank (1995), Swain and Morin 155 (1996), and Craig et al. (2005).

156 The geographic range was estimated as the minimum area over which a specified 157 percentage of Greenland halibut was distributed. The minimum area over which $95 \%$ of 158 Greenland halibut were distributed was used as the measure of geographic range and an 159 index of distribution, which was calculated for the four size classes. This index depends 160 only on spatial spread, which is independent of the estimate of abundance (Swain and 161 Sinclair, 1994). Cumulative distribution functions weighted by catch $\mathrm{F}(c)$ of Greenland 162 halibut were calculated as:

$$
\mathrm{F}(\mathrm{c})=100 \frac{\sum_{h=1}^{K} \sum_{\mathrm{i}=1}^{\mathrm{n}_{\mathrm{h}}} \frac{\mathrm{A}_{\mathrm{h}}}{\mathrm{A}_{\mathrm{T}}} \mathrm{X}_{h i} \mathrm{I}}{\sum_{h=1}^{K} \sum_{\mathrm{i}=1}^{n_{\mathrm{h}}} \frac{\mathrm{A}_{\mathrm{h}}}{\mathrm{A}_{\mathrm{T}}} \mathrm{X}_{h i}} \quad \text { Where } I=\left\{\begin{array}{l}
1 \text { if } X_{h i} \leq c \\
0 \text { otherwise }
\end{array}\right.
$$


164 where $\mathrm{n}_{h}$ is the number of trawl tows in stratum $h, X_{h i}$ is the number of Greenland halibut 165 caught in tow $i$ in stratum $h$, and $c$ is a level of Greenland halibut density (i.e., number per 166 standard tow); the other symbols are as described for equation (1). $F(c)$ provides an 167 estimate of the percentage of Greenland halibut (for a given sex and size class in a given 168 year) occurring at a local density of $c$ or less. The cumulative area $\mathrm{G}(c)$ in relation to 169 Greenland halibut catch was calculated as:

$\mathrm{G}(\mathrm{c})=100 \sum_{h=1}^{K} \sum_{i=1}^{n_{h}} \frac{A_{h}}{A_{T}} I \quad$ Where $I=\left\{\begin{array}{l}1 \text { if } X_{h i} \leq c \\ 0 \text { otherwise }\end{array}\right.$

170

$171 \mathrm{~F}$ was evaluated at intervals of 0.1 , and the density $\mathrm{c}_{05}$ corresponding to $\mathrm{F}=5$ was

172 calculated. $\mathrm{G}\left(c_{05}\right)$ is the estimated area containing the most sparsely distributed $5 \%$ of the 173 catch (including areas where no fish were caught). Thus, the minimum area containing 95\% 174 of Greenland halibut $\left(\mathrm{D}_{95}\right)$ is given by:

$D_{95}=A_{T}-G\left(c_{05}\right)$

175

176

177 were spread were also estimated. Relationships between indices of distribution area of a

178 size class and indices of abundance of that size class were examined in order to take into

179 account the difference in spatial distribution between size groups. The distribution area of 180 each size class was also examined in relation to the index of total population abundance.

181 Mean distributional areas occupied by the different size classes of Greenland halibut for 182 periods of low and high abundance levels were also compared. In the absence of 183 homogeneity in variances, non-parametric Friedman test was used to compare occupied 184 areas in relation to size class and abundance level (i.e. low and high). 
185 Regional variation in distribution and rates of local density change

186 Relationship between local density and relative abundance was used to examine density187 dependent spatial distributions at the regional scale (Marshall and Frank, 1995; Swain and 188 Morin, 1996; Craig et al. 2005). According to Myers and Stokes (1989), the relationship 189 between local density $y_{h i t}$ and total population abundance $N_{t}$ is described by a power 190 function:

$y_{h i t}=\alpha_{h} N_{t}^{\beta_{h}}$

192 where $y_{\text {hit }}$ represents Greenland halibut catch (for a particular size class) in tow $i$ of stratum

$193 h$ in year $t$ and $N_{t}$ is the measure of total population abundance in year $t . \beta_{h}$ describes how 194 regional catch rate varies with relative abundance. $\beta_{h}$ was estimated using the following 195 generalized linear model:

$E\left[y_{h i t}\right]=\mu_{h t}=\exp \left(a_{h}+\beta_{h} \ln N_{t}\right)$

196

197

198

199

200

201

202 quality. In the same way as was done by Swain and Morin (1995), mean catch rate per

203 stratum for the years of lowest abundance was used as an index of habitat quality for each

204 stratum to test this assumption.

205 Generalized additive models (GAM)

206 Generalized Additive Models (GAM) (Hastie and Tibshirani, 1990) were used to examine 
207 the influence of ambient environmental conditions (spatial location, depth, temperature, and

208 DO) and annual population abundance on the number of fish caught per tow at the different

209 stations in the EGSL. GAMs are non-parametric generalizations of multiple linear

210 regressions that are not restricted to specific functional relationships (i.e., linearity) or

211 underlying statistical distributions (i.e., normality) of the data (Hastie and Tibshirani, 1990,

212 Swartzman et al., 1992). Thus, GAMs can be advantageous for examining environmental

213 and stock relationships that are unlikely to be monotonic, linear, or parametric (Maravelias

214 and Reid, 1997). The dependent variable (i.e., number of fish per tow) was modeled as the

215 additive sum of the predictor variables, whereby scatterplot smoothings replace the least-

216 squares estimates used in multiple linear regressions (Hastie and Tibshirani, 1990). The

217 general form of a GAM assumes that the mean response $(\mu)$ is related to the predictor

218 variables $\left(\mathrm{X}_{1}, \ldots, \mathrm{X}_{\mathrm{p}}\right)$ by the following relationship:

$\mathrm{g}(\mu)=\alpha+\sum_{\mathrm{j}=1}^{\mathrm{p}} f_{j}\left(\mathrm{X}_{\mathrm{j}}\right)$

220 where $g(\mu)=$ link function, defines the relationship between the response and the additive

221 predictor, $\alpha=$ intercept term, and $f \mathrm{j}$ is the unspecified smoothing function. The observed

222 response is assumed to obey some type of underlying exponential statistical distribution

223 (e.g., Gaussian, Poisson, binomial, or Gamma distribution) with the specified mean, $\mu$

224 (Hastie and Tibshirani, 1990). Appropriate link functions and error distributions were

225 chosen on the basis of residual plots (Hastie and Tibshirani, 1986; Swartzman et al., 1992;

226 Borchers et al., 1997). A GAM with a log-link function and Gaussian error distribution was

227 found to be adequate for the data modeled here. The GAM used cubic B-spline smoother 
228 for mean annual abundance, latitude, longitude, depth, temperature and oxygen to explain 229 the variability in the number of fish catch per tow. GAMs explaining the largest total 230 deviance were selected as final models.

231 Separate GAMs for each size class were used to determine the importance of 232 population abundance of each size class and environmental factors on the catches of that 233 size-class. The first analyses applied over the entire time series (1990-2010) did not include 234 DO as a dependent variable. Separate GAMs for the 2004-2010 period were used to 235 determine the importance of DO on the Greenland halibut catches. In all models, a 236 backfitting method was used to determine the relative contribution of the different 237 variables. The relative contribution of the variables to the model was determined by the 238 change in the total deviance explained by the full model and the model with the different 239 selected variables dropped.

240 Finally, the spatial distribution of DO concentrations in the EGSL was examined 241 using a GAM linking DO to longitude, latitude, depth and temperature. Annual variations 242 between 2004 and 2010 were also examined by including a year effect in the model. All 243 statistical analyses were performed using the R version 2.12.0 software. 


\section{RESULTS}

246 Between 1990 and 2010, there were periods of low and high abundance for both Greenland 247 halibut juveniles and adults in the estuary and Gulf of St. Lawrence (Fig. 1). The variations 248 in abundance for the different size classes were well correlated between both the DFO and 249 sentinel fishery surveys $\left(\mathrm{r}^{2}\right.$ between 0.49 and 0.58). However, the analysis of the 250 relationships between spatial distribution and abundance indices was restricted to DFO 251 surveys, the time series for these surveys being more extended in terms of time and spatial 252 coverage; the sentinel fishery did not cover 4 strata in the St. Lawrence estuary.

253 Low juvenile (fish between 15 and $31 \mathrm{~cm}$ ) abundance was observed up to 1997, but 254 their abundance was high from 1998 to 2010 (Fig. 1a). The 32-43 cm size class was 255 represented by mature males and immature females. To take into account this size-specific 256 difference in maturity, abundance was first analyzed according to the sex of individuals. 257 Based on the similar results obtained for both sexes male and female data were 258 subsequently pooled for all analysis (Fig. 1b). Two distinct periods of abundance were 259 observed for this size class: a low abundance period between 1990 and 1999 and a high 260 abundance period between 2000 and 2010 with a maximum abundance level reached in 261 2003. The abundance of fish longer than $44 \mathrm{~cm}$, largely represented by mature females 262 (68\% of females and 30\% of males), was low between 1990 and 2002. From 2003 onward, 263 the abundance remained at a high level (Fig. 1c).

264 The mean catch rate of juveniles was $16 \pm 8$ fish per standard tow during the period 265 of low abundance, whereas it was $53 \pm 18$ fish per standard tow in the period of high 266 abundance. A five-fold increase in the mean catch rate for the $32-43 \mathrm{~cm}$ size class was 267 observed between the period of low and high abundance; mean catch increasing from $8 \pm 3$ 
268 to $41 \pm 11$ fish per standard tow. The abundance of larger Greenland halibut $(\geq 44 \mathrm{~cm})$

269 varied from $3 \pm 1$ to $8 \pm 1$ fish per standard tow during periods of low and high abundance, 270 respectively.

271 Geographic distribution

272 During periods of low abundance, juvenile fish and fish in the $32-43 \mathrm{~cm}$ size class mainly 273 occupied the eastern part of the estuary and north of Anticosti Island (Fig. 2a, c). The area 274 occupied by these two size classes increased with higher catch rate; during periods of high 275 abundance, they occupied the whole St. Lawrence Estuary and extended their distribution 276 to beyond the estuary (Fig. 2). Juveniles were virtually absent in southeast part of the EGSL 277 (i.e. $\sim 48^{\circ} \mathrm{N}$ and $-60^{\circ} \mathrm{W}$ ) during periods of both low and high abundance. Fish longer than $27844 \mathrm{~cm}$ showed a more homogeneous distribution throughout the St. Lawrence system (Fig. 279 2) compared to the two other size classes.

280 Abundance in relation to distribution

281 Significant correlations were observed between the indices of distributional area $\left(\mathrm{D}_{95}, \mathrm{D}_{75}\right.$, 282 and $\left.\mathrm{D}_{50}\right)$ of a size class and the relative abundance of that size class $\left(Y_{s, t}\right)$ (Table 1). Areas 283 including $95 \%$ and $75 \%$ of Greenland halibut were significantly density-dependent and 284 increased as abundance increased for juveniles and adult fish longer than $44 \mathrm{~cm}$ (Fig. 3).

285 The relationship between the area including $50 \%$ of the fish and relative abundance 286 was only significant for juveniles (Table 1). No relationship ( $\mathrm{p}>0.05)$ was found between 287 distributional area $\left(\mathrm{D}_{95}, \mathrm{D}_{75}\right.$ and $\left.\mathrm{D}_{50}\right)$ and relative abundance for Greenland halibut in the $288 \quad 32-43 \mathrm{~cm}$ size range. Relationships between distributional area of the different size classes 289 with the index of total population abundance $\left(Y_{t}\right)$ are with a few exceptions similar to those 290 obtained using size-specific abundance index $\left(Y_{s, t}\right)$ (Table 1). Changes in the significance 
291 levels for $D_{95}$ and $D_{75}$ for the $32-43 \mathrm{~cm}$ size class and $D_{75}$ for fish $\geq 44 \mathrm{~cm}$ nevertheless

292 correspond to similar and low coefficients of determination.

293 Distributional areas occupied by $95 \%, 75 \%$, and $50 \%$ of the juvenile fish were

294 smaller than for fish longer than $32 \mathrm{~cm}$ (Table 2). Friedman non-parametric tests indicated 295 significant effects of both size class $(\mathrm{p}<0.004)$ and abundance level (i.e. low vs high) $296(\mathrm{p}<0.02)$ on distributional areas with no significant interaction between the two factors 297 ( $\mathrm{p}>0.13)$. At low abundance, the areas occupied by juvenile fish $(15-31 \mathrm{~cm})$ for all 298 percentages of fish represented $53 \%$ to $73 \%$ of the areas occupied by the two other size 299 classes. At high abundance, areas occupied by the juveniles represented $80 \%$ to $89 \%$ of the 300 areas occupied by fish longer than $32 \mathrm{~cm}$.

\section{Regional variation in distribution and rates of local density change}

302 Significant changes in local density in relation to abundance were observed in most strata 303 for the three size classes (i.e. slope $\beta$ significantly different than 0 ). The regressions 304 between rate of local density change $(\beta)$ and the index of habitat quality (i.e. mean catch 305 rate in a stratum during low abundance) were not significantly $(\mathrm{p}>0.15)$ different than 0 for 306 each size class (Fig. 4). Thus, there was no evidence that the rate of increase in marginal 307 habitat (i.e. low index of habitat quality) was higher than in optimal habitat when the 308 abundance increased. Instead, a proportional increase in abundance is observed for the three 309 size classes in both optimal and marginal habitats (Fig. 4).

310 Abundance in relation to abiotic factors

311 The following GAM formulation explained the largest deviance in the catches of Greenland 312 halibut for the three different size classes during the 1990 to 2010 period: 
$313 \log _{e}\left(Y_{s, t}+1\right)=s\left(\bar{Y}_{s, t}\right)+s($ longitude $:$ latitude $)+s($ depth $)+s($ temperature $)$

314 For the 2004-2010 period that includes DO as an additional variable the model explaining 315 the largest deviance was:

$316 \log _{e}\left(Y_{s, t}+1\right)=\bar{Y}_{s, t}+s($ longitude $:$ latitude $)+s($ depth $)+s($ temperature $)+s($ oxygen $)$

317 GAM regressions indicated significant non-linear relationships for the different 318 covariates on the catches (i.e. number of fish per standard tow) of the three Greenland 319 halibut size classes (Tables 3 and 4). Final models for the entire time period explained 320 between $59 \%$ and $77 \%$ of the variations in the catches (Table 3). For the 2004-2010 period, 321 the GAM including DO as an additional dependent variable explained $73 \%$ to $86 \%$ of the 322 variations in the GH catches (Table 4).

323 The highest juvenile concentrations (i.e. $15-31 \mathrm{~cm}$ ) in both low and high population 324 abundance periods were observed towards the western part of the estuary and Gulf of St. 325 Lawrence (west of $66^{\circ} \mathrm{W}$ ) and in a smaller area north of Anticosti Island centered at $32649.5^{\circ} \mathrm{N} 62^{\circ} \mathrm{W}$ (Fig. 5). In both areas, largest concentrations were found at depths greater 327 than $200 \mathrm{~m}$ and temperatures between 5 and $6^{\circ} \mathrm{C}$. The number of fish per tow was also 328 positively related to the mean annual abundance of the juveniles (Fig. 5). Concentrations of 329 fish in the $32-43 \mathrm{~cm}$ size class followed a very similar pattern. The highest concentrations 330 were observed in the same areas, depths and temperatures with number of fish per tow 331 increasing with higher mean annual abundance of the $32-43 \mathrm{~cm}$ fish (Fig. 6). Larger 332 Greenland halibut $(\geq 44 \mathrm{~cm})$ as well were found in higher concentrations in the same depth 333 and temperature ranges but had a different spatial distribution (Fig. 7). High concentrations 334 were centered in three distinct areas; the St. Lawrence estuary $\left(\sim 48.7^{\circ} \mathrm{N} 68^{\circ} \mathrm{W}\right)$, the 
335 Gaspésie peninsula $\left(\sim 49.5^{\circ} \mathrm{N} 65^{\circ} \mathrm{W}\right)$, and the northeast part of the Gulf $\left(\sim 50.2^{\circ} \mathrm{N} 58.5^{\circ} \mathrm{W}\right)$.

336 The number of fish per tow was also positively related to the mean annual abundance of 337 that size class of fish.

338 For all size classes, the relative contribution of the mean annual abundance of the fish 339 in explaining the variability in the catches was less important than spatial location and 340 environmental factors (Table 5). The decrease in total deviance explained when mean 341 annual abundance was dropped from the final models indicates a relative contribution 342 between 7 and $9.2 \%$ of annual abundance indices in explaining variability in the catches.

343 The spatial location had the highest relative contribution to the variations in the catches of 344 the juveniles and fish in the $32-43 \mathrm{~cm}$ fish, the total deviance explained by the models 345 decreasing by 31 and 25\%, respectively, when longitude and latitude were dropped from 346 the final models. The relative contribution of depth and temperature is lower than spatial 347 location (14.3 and $17.6 \%$ change in deviance, respectively) but more important than the 348 mean annual abundance of the fish (Table 5). In large fish ( $\geq 44 \mathrm{~cm})$, spatial location and 349 environmental factors (i.e. depth and temperature) had equal relative contributions to the 350 variations in the catches.

351 DO included as an additional environmental variable had a significant influence on 352 the variations in the catches of all size classes for the period between 2004 and 2010 (Table 353 4). Fish of all sizes were largely found in waters characterized by low DO levels $(<130$ $354 \mu \mathrm{mol} / \mathrm{L})$. Highest concentrations of fish were observed in waters with the lowest DO levels 355 (Figs 8, 9 and 10). Sixty-seven percent of the sets in the survey with the highest catch rates 356 were located in areas with DO levels lower than $70 \mu \mathrm{mol} / \mathrm{L}$.

357 As observed in the first series of analysis, all covariates for the models covering the 
358 2004-2010 period had significant non-linear effects on the catches with very similar shape 359 of the smooth functions (Figs 8, 9 and 10). The only exception was for larger fish where, in 360 the final GAM, temperature had no significant effect on catches. Variations in the mean 361 annual abundance of fish had a significant but minor relative contribution (\% change in 362 deviance between 0.3 and 0.6 ) to the variability in catches (Table 6). The relative 363 contribution of individual covariates indicated a higher contribution of spatial location on 364 the variability of juvenile catches (8.3\% change in deviance) and significant but lower 365 relative contribution of DO and depth (3.5 and $2.9 \%$ change in deviance). For Greenland 366 halibut of the two other size classes, spatial location and depth had comparable relative 367 contributions in explaining the variability in the catches (Table 6). For all size classes, the 368 combined contribution of all covariates is lower than the total deviance explained by the 369 final models indicating some correlation between covariates. The increased relative 370 contribution of spatial position and depth and temperature when these covariates are 371 combined with DO indicate the strong association between DO and Greenland halibut 372 catches (Table 6).

373 Ninety-five percent of the variability in DO concentrations in the EGSL between 3742004 and 2010 is explained by a GAM including longitude, latitude, depth and temperature. 375 Year effect although significant has a very minor relative contribution to the model (i.e. $3760.2 \%$ change in total deviance when dropped from the full model). Smooth functions for the 377 covariates indicate that low DO concentrations are largely associated with depths between 378200 and $350 \mathrm{~m}$ and temperatures between 4 and $6^{\circ} \mathrm{C}$ (Fig. 11). Moreover, DO 379 concentrations decrease in a westward direction with lowest values in the St. Lawrence 380 estuary $\left(68^{\circ} \mathrm{W}\right)$ 


\section{DISCUSSION}

383 The spatial distribution of Greenland halibut in the estuary and the Gulf of St. Lawrence

384 (EGSL) is dependent on fish size, population abundance, and physical characteristics of the

385 environment. Variations in local fish density indicate that the major area of occupancy for

386 juvenile fish $(<31 \mathrm{~cm})$ is the western part of the EGSL ecosystem. The highest juvenile

387 concentrations are found in the St. Lawrence estuary (west of longitude $67^{\circ} \mathrm{W}$ ) regardless

388 of stock abundance. The areas containing $50 \%, 75 \%$, and $95 \%$ of juvenile fish are density-

389 dependent, with the area of occupancy expanding as population abundance increases.

390 Although significant, the stock abundance of juveniles explains a limited proportion (27 to

$39132 \%$ ) of the variability in their spatial distribution. Abundance indices and spatial

392 distributions that are calculated from the same survey data (i.e. DFO surveys) cannot be

393 considered as independent. However, the good correspondence between abundance indices

394 from DFO and sentinel fishery surveys indicates a low potential for spurious correlations

395 from unmeasured factors related to or influencing the DFO surveys. Due to the shorter time

396 series and lower spatial coverage of the sentinel fishery survey, it was thus considered

397 acceptable and preferable to only use DFO survey data for the analysis.

398 The area of occupancy for juveniles is smaller than for larger-sized groups (i.e., $>$

$39932 \mathrm{~cm}$ ). The area occupied by the different percentages of juvenile fish (i.e., $\mathrm{D}_{50}, \mathrm{D}_{75}$, and $400 \mathrm{D}_{95}$ ) represented 54 to $73 \%$ of the area occupied by larger fish during periods of low stock 401 abundance and between 81 and $88 \%$ for periods of higher stock abundance. Based on 402 variations in local fish density and restricted areas of occupancy, the St. Lawrence estuary 403 can be considered the primary nursery area for the EGSL Greenland halibut stock. The very 404 low abundance of juvenile fish in summer and winter surveys conducted at the end of the 
4051970 s in the Gulf of St. Lawrence (eastern part) also supports this assumption (Bowering, 406 1982). At the time of these surveys which did not cover the St. Lawrence estuary, it was 407 even hypothesized that recruitment may come from outside the Gulf of St. Lawrence 408 (Bowering, 1982). Size frequency distributions of juvenile Greenland halibut indicate that 409 fish smaller than $31 \mathrm{~cm}$ consist of one- and two-year-old fish (Morin and Bernier 2003, 410 DFO, 2011). Thus, juvenile Greenland halibut that settle in the St. Lawrence estuary appear 411 to be sedentary for at least their first two years of life.

412 GAM analyses indicate that the abundance of juvenile fish is associated with 413 geographic location, environmental factors and mean annual abundance (i.e. population 414 density). Longitude, latitude, depth, temperature and annual abundance explained $76.6 \%$ of 415 the variability in juvenile catches (i.e. number of fish per standard tow) during the whole 416 period (1990-2010). Spatial location (longitude and latitude) alone accounted for most of 417 this variation. The relative contribution of environmental variables (i.e., depth and 418 temperature) in explaining the variability in juvenile catches was lower than spatial location 419 but more important than the variations in the mean annual abundance of the juveniles. 420 During the period of high stock abundance (2004-2010), 82.9\% of the variability in 421 juvenile catches was explained by all the covariates studied with spatial location (longitude 422 and latitude) explaining the largest variability when considering individual effects of each 423 single covariate $(8.3 \%$ change in total deviance compared to 0.6 to $3.5 \%$ for other 424 covariates). Cross correlations between DO, spatial location, temperature and depth result 425 in a high association between catches and low DO concentrations. Combination of spatial 426 location and DO explained $37.1 \%$ of the variability in the juvenile catches while 427 combination of depth, temperature and DO explained $21.9 \%$ of the variability in the 
428 catches.

429 When systematic measurements of dissolved oxygen were done (2004-2010), areas

430 with the lowest DO concentrations (hypoxic areas) were located in the western part of the

431 EGSL ecosystem (i.e., St. Lawrence estuary; $49^{\circ} \mathrm{N}$ and west of $64^{\circ} \mathrm{W}$ ) at depths ranging 432 between 200-300 m. At both low and high abundances, the highest juvenile concentrations

433 were observed in areas characterized by these low DO levels. DO concentrations in the 434 bottom waters of the lower St. Lawrence estuary were stable, with a mean value of $65 \mu \mathrm{mol}$ $435 \mathrm{~L}^{-1}$ from the mid-1980s to 2003 (Gilbert et al., 2005). Measurements made in the same area 436 between 2004 and 2010 in the present study indicate identical and stable concentrations

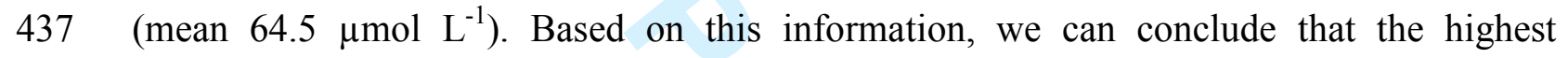
438 concentrations of juvenile fish during the period of low stock abundance were in the 439 hypoxic areas. Thus, during periods of both low and high abundance juvenile fish 440 preferentially selected habitats characterized by the lowest dissolved oxygen levels. DO 441 levels in these areas ( 20\% saturation) are not severe enough to result in an active 442 displacement of juvenile fish out of the St. Lawrence estuary.

$443 \quad$ Under the theory of density-dependent habitat selection (Fretwell and Lucas, 1970; 444 MacCall, 1990), spatial variations in local density reflect gradients in resource availability, 445 with local density being highest where resources are abundant (optimal habitat) and lowest 446 where resources are scarce (marginal habitat). At low abundance levels, individuals should 447 occupy the optimal habitats; as abundance increases, density will increase in these preferred 448 habitats and individuals will also begin to occupy marginal habitats. During the period 449 covered by the present study, juvenile Greenland halibut appear to follow this expected 450 pattern of expansion in habitat. Density-dependent habitat selection provides a possible 
451 explanation for the change in juvenile distributional area between periods of low and high 452 abundance in the EGSL. However, correlations between abundance and occupied area do 453 not necessarily demonstrate a causal relationship or prove the presence of density454 dependent habitat selection (Shepherd and Litvak, 2004). Further work showing changes in 455 fish condition and growth in optimal habitats, for instance, would be necessary to clearly 456 demonstrate the presence of density-dependent habitat selection.

457 Contrary to predictions in changes in local density in optimal versus marginal habitats 458 (Marshall and Frank, 1995), the rate of increase in local density in the marginal habitats 459 was not higher than in the optimal habitats. Based on this result and the fact that variations 460 in the mean annual abundance of the juveniles (i.e. density) explains a limited proportion of 461 the variability in the spatial distribution of the juveniles, the spatial dynamics are probably 462 better defined by a proportional density model (Hilborn and Walters, 1992). In this model, 463 the area occupied by the fish does not vary and an increase in population abundance is 464 associated with an increase in fish density at all points, fish density remaining a constant 465 proportion of population abundance. These results for juvenile Greenland halibut are 466 similar to those reported by Swain and Morin (1996) for American plaice in the southern 467 Gulf of St. Lawrence and for Atlantic cod in the northern Gulf of St. Lawrence (NAFO 468 Division 4R) (Tamdrari et al., 2010). No tendency was observed for percent changes in 469 plaice or cod density to be greater in marginal habitats than in optimal habitat as population $470 \quad$ size changed.

471 No apparent density-dependent effect on area of occupancy was observed for the 32$47243 \mathrm{~cm}$ size class. For the largest size-class $(\geq 44 \mathrm{~cm})$, a significant density-dependent effect 473 was observed for the areas containing $95 \%$ and $75 \%$ of the fish. However, the maximum 
474 area of occupancy was rapidly reached. At low population abundances, the areas containing $47595 \%$ and $75 \%$ of the fish were approximately 43000 and $24000 \mathrm{~km}^{2}$, respectively. For 476 higher population abundances, the mean areas of occupancy were more or less stable at $\sim$ 47753000 and $27000 \mathrm{~km}^{2}$, respectively, even with a two to three-fold increase in population 478 size. The area containing $50 \%$ of the fish did not change within the observed range in 479 population abundance. These observations imply that the most suitable habitats occupied by 480 larger Greenland halibut (i.e., $>32 \mathrm{~cm}$ ) are not saturated and that local density may 481 increase without leading to intra-specific competition. The absence of relationships between 482 the rate of change in local fish density and the indices of habitat quality suggests that the 483 spatial dynamics of larger Greenland halibut are similar to that observed for the juveniles.

484 Local density increased with population abundance but fish density remained a constant 485 proportion of population abundance.

486 The spatial distribution and local density of juvenile fish is different inform that of 487 larger Greenland halibut. Juveniles are highly concentrated in the St. Lawrence estuary 488 (identified as the major nursery area) while adults are more widely distributed in the Gulf. 489 Similar differences in spatial distribution have been observed in other Greenland halibut 490 populations, with clear separations between juvenile and adult spatial distributions being 491 noted in the Barents Sea and in west Greenland waters (Jørgensen, 1997a; Albert, 2003).

492 The highest concentrations of juvenile Greenland halibut observed in the hypoxic 493 areas of the St. Lawrence ecosystem indicate that the current levels of dissolved oxygen $(\sim$ $49420 \%$ saturation) are not at threshold levels that will influence the spatial distribution of this 495 species. Moreover, the high index of recruitment observed in several years since 1990 (i.e., 496 1997, 1999, 2002, and 2004) also suggests that these hypoxic waters are not causing 
497 recruitment failures for Greenland halibut (DFO, 2011). The high catches of fish in waters 498 with low DO concentrations may indicate an enhanced catchability of Greenland halibut 499 due to impaired gear trawl avoidance. However, studies on Atlantic cod and Greenland 500 halibut demonstrated that both species could hardly keep up with the towing speed of the 501 trawls $(100-180 \mathrm{~cm} / \mathrm{sec} ; 2.2-3.9$ body length/sec) for a prolonged period of time, even in 502 normoxia (Dutil et al, 2007, Albert et al., 2003). Trawl avoidance in Greenland halibut was 503 related to detection time, take-off and direction of swimming (Albert et al. 2003). Given the 504 limited capacity for sustained swimming (i.e. cruising speed related to aerobic metabolic 505 processes), burst swimming, an anaerobic metabolic process independent of ambient DO, 506 may be more important for escapement. It was also observed that escapement beneath the 507 ground-gear which is independent of ambient DO, was higher in smaller fish. Acclimation 508 to hypoxia may also increase subsequent hypoxia tolerance and swimming performance $(\mathrm{Fu}$ 509 et al., 2011). In goldfish (Carratius auratus) an increase of $18 \%$ in Ucrit (sustained 510 swimming for $48 \mathrm{~h}$ at $70 \%$ of critical swimming speed) was observed following acclimation 511 to hypoxia (Fu et al., 2011). Although increase catchability at low DO cannot be 512 completely rejected we conclude that the low DO concentrations and the range in DO 513 concentrations where Greenland halibut are mostly found ( 20 to $60 \%$ saturation levels) 514 do not result in different catchability between areas in the EGSL.

515 Habitat selection by juvenile fish may result from the high tolerance of the fish to 516 low DO levels and interactions between the effects of density-dependent resources (i.e., 517 spatial variation in food availability) and density-independent factors (i.e., depth, 518 temperature). It has been shown that under laboratory conditions, juvenile Greenland 519 halibut could tolerate DO levels as low as $14.89 \pm 0.92 \%$ saturation (Dupont-Prinet, pers. 
520 comm.). Small Greenland halibut are also known to feed mainly on shrimp Pandalus

521 borealis, capelin Mallotus villosus, and large zooplankton species such as euphausids, 522 mysids and hyperiid amphipods in the EGSL (Fréchet, 1987; Savenkoff et al., 2009). These

523 species are all abundant in the St. Lawrence estuary (Plourde et al., 2001; 2002; 2003; 524 2010).

525 Many studies have demonstrated that this area, characterized by up-welling, is very 526 productive and favours biomass accumulation (Lavoie et al., 2007; Lesage et al., 2007; 527 Ouellet, 2007; Plourde and McQuinn, 2010). However, hypoxic conditions may limit the 528 growth of juvenile fish even if food resources are abundant. For example, the lower 529 tolerance limit in oxygen concentration for Atlantic cod is $88 \mu \mathrm{mol} \mathrm{L}^{-1}$ (i.e. $28 \%$ 530 saturation) (Plante et al., 1998) but oxygen saturation levels up to $70 \%$ can limit growth 531 capacity by affecting the metabolic scope, which reduces food intake of fish (Chabot and 532 Dutil, 1999). Further work on the growth of juvenile Greenland halibut is necessary to 533 examine this possibility.

534 Hypoxic areas in the EGSL could represent a refuge from predators for juvenile 535 Greenland halibut. Based on diet composition, very low predation has been observed on 536 juveniles (Savenkoff et al., 2009). Cannibalism has been observed in other stocks 537 (Rodriguez-Marin et al., 1995; Jørgensen, 1997b; Woll and Gundersen, 2004; Dwyer et al., 538 2010). However, cannibalistic behaviour should be of minor importance for Greenland 539 halibut in the EGSL based on spatial distribution and range in fish sizes. As mentioned, the 540 different spatial distributions of juveniles and adults at higher abundance levels should limit 541 interactions between fish of different sizes. Moreover, Greenland halibut caught in the 542 EGSL rarely exceeds $56 \mathrm{~cm}$ in length (DFO, 2006) while cannibalism usually occurs in fish 
543 larger than $69 \mathrm{~cm}$ (Dwyer et al., 2010). Based on the high tolerance level of sprat (Sprattus 544 sprattus) to low oxygen saturation level (i.e. $7 \% \mathrm{O}_{2}$ ) it has been hypothesized that 545 overwintering sprat could exploit hypoxic waters as a predator refuge (Kaartvedt et al. 546 2009).

547 The spatial distribution of juvenile Greenland halibut would indicate that the current 548 DO levels in the St. Lawrence estuary have no direct effect on fish distribution and that 549 possible negative effects associated with these hypoxic areas (i.e., survival and growth) 550 may be counterbalanced by possible advantages associated with higher food availability 551 and/or refuge against from predators.

\section{CONCLUSION}

553 Our results suggest that the spatial dynamics of Greenland halibut in the EGSL follow a 554 proportional density model where the rate of increase in local density is associated with 555 population abundance. Spatial location, depth and temperature explain a large proportion of 556 the variability in the catches. Juvenile distribution clearly indicates the St. Lawrence 557 estuary is the major nursery area for the EGSL population. Habitats selected by Greenland 558 halibut are characterized by low DO levels and the strong association between higher fish 559 densities and the low DO concentrations indicates a high tolerance of Greenland halibut to 560 hypoxia. It also suggests that negative effects, if present, could be compensated by other 561 factors like food availability and/or refuge from predation. Further work on the influence of 562 hypoxia on fish condition and growth performance of Greenland halibut is necessary to 563 explore these possibilities. 


\section{ACKNOWLEDGMENTS}

566 This project was funded by the Natural Sciences and Engineering Research Council of

567 Canada (Strategic grant No. STPGP 365115-08 to C. Audet, D. Gilbert, Y. Lambert, D.

568 Chabot and R. Tremblay) and the Canadian department of Fisheries and Oceans (DFO). We

569 thank the crew of the RV "Teleost", and numerous technicians for their help in research

570 cruises and DFO for the access to research surveys database. We thank the two anonymous

571 reviewers for their constructive comments on an earlier version of the manuscript.

572 
573

574

575

576

577

578

579

580

581

582

583

584

585

586

587

588

589

590

591

592

593

594

595

596

597

598

599

600

601

602

603

604

605

606

\section{REFERENCES}

Albert, O.T. (2003) Migration from nursery to spawning area in relation to growth and maturation of Greenland halibut (Reinhardtius hippoglossoides) in the Northeast Arctic. J. Northw. Atl. Fish. Sci. 31: 113-125.

Albert, O.T., Harbitz, A., Høines, A.S., (2003) Greenland halibut observed by video in front of survey trawl: behaviour, escapement, and spatial pattern. J. Sea Res. 50: 117127.

Atkinson, D.B., Rose, G.A., Murphy, E.F. and Bishop, C.A. (1997) Distribution changes and abundance of northern cod (Gadus morhua), 1981-1993. Can. J. Fish. Aquat. Sci. 54: 132-138.

Borchers, D.L., Buckland, S.T., Priede, I.G. and Ahmadi, S. (1997) Improving the precision of the daily egg production method using generalized additive models. Can. J. Fish. Aquat. Sci. 54: 2727-2742.

Bourdages, H., Archambault, D., Bernier, B., Fréchet, A., Gauthier, J., Grégoire, F., Lambert, J. and Savard, L. (2008) Preliminary results from the groundfish and shrimp multidisciplinary survey in August 2008 in the Northern Gulf of St. Lawrence. Can. Data Rep. Fish. Aquat. Sci. 1210.73pp.

Bourdages, H., Archambault, D., Bernier, B., Fréchet, A., Gauthier, J., Grégoire, F., Lambert, J. and Savard, L. (2010) Preliminary results from the groundfish and shrimp multidisciplinary survey in August 2009 in the Northern Gulf of St. Lawrence. Can. Data Rep. Fish. Aquat. Sci. 1226. 72pp.

Bourdages, H.L., Savard, L., Archambault, D. and Valois, S. (2007) Results from the August 2004 and 2005 comparative fishing experiments in the northern Gulf of St. Lawrence between the CCGS Alfred Needler and the CCGS Teleost. Can. Tech. Rep. Fish. Aquat. Sci. 2750. 57pp.

Bowering, W.R. (1982) Population dynamics of Greenland halibut in the Gulf of St. Lawrence. J. Northw. Atl. Fish. Sci. 3: 141-147.

Castonguay, M., Rollet, C., Fréchet, A., Gagnon, P., Gilbert, D. and Brêthes, J.C. (1999) Distribution changes of Atlantic cod (Gadus morhua L.) in the northern Gulf of St Lawrence in relation to an oceanic cooling. ICES J. Mar. Sci. 56: 333 -344.

Chabot, D. (2004) Chronic Non-Lethal levels of hypoxia limit distribution and growth of Atlantic cod (Gadus morhua) in the northern Gulf of St. Lawrence, Canada. In: Fish Physiology, Toxicology, and Water Quality. Proceedings of the Seventh International Symposium, Tallinn, Estonia: EPA, Ecosystems Research Division. pp. 183-205. 
607 Chabot, D. and Dutil, J.D. (1999) Reduced growth of Atlantic cod in non-lethal hypoxic conditions. J. Fish Biol. 55: 472-491.

609

610

611

612

613

614

615

616

617

618

619

620

621

622

623

624

625

626

627

628

629

630

631

632

633

634

635

636

637

638

639

640

Cote, D., Moulton, S., Frampton, P.C.B., Scruton, D.A. and McKinley, R.S. (2004) Habitat use and early winter movements by juvenile Atlantic cod in a coastal area of Newfoundland. J. Fish Biol. 64: 665-679.

Craig, J.K., Crowder, L.B. and Henwood, T.A. (2005) Spatial distribution of brown shrimp (Farfantepenaeus aztecus) on the northwestern Gulf of Mexico shelf: effects of abundance and hypoxia. Can. J. Fish. Aquat. Sci. 62: 1295-1308.

Crecco, V. and Overholtz, W.J. (1990) Causes of Density-Dependent Catchability for Georges Bank Haddock (Melanogrammus aeglefinus). Can. J. Fish. Aquat. Sci. 47: 385-394.

Csirke, J. (1980) Recruitment in the Peruvian anchovy and its dependence on the adult population. In: The assessment and management of pelagic fish stocks. Saville, A. (ed.) Rapp. P.V. Réun. CIEM. 177. 307-313pp.

D'Amours, D. (1993) The distribution of cod (Gadus morhua) in relation to temperature and oxygen level in the Gulf of St. Lawrence. Fish. Oceanogr. 2: 24-29.

DFO (2006) Assessment of the Greenland halibut Stock in the Gulf of St. Lawrence (4RST) in 2005. DFO Can. Sci. Advis. Sec. Sci. Advis. Rep. 2006/011. 11pp.

DFO (2010) Assessment of the Greenland Halibut Stock in the Gulf of St. Lawrence (4RST) in 2009. DFO Can. Sci. Advis. Sec. Sci. Advis. Rep. 2010/028. 28pp.

DFO (2011) Assessment of the Greenland Halibut Stock in the Gulf of St. Lawrence (4RST) in 2010. DFO Can. Sci. Advis. Sec. Sci. Advis. Rep. 2011/013. 13pp.

Diaz, R.J. and Rosenberg, R. (1995) Marine benthic hypoxia: a review of its ecological effects and the behavioural responses of benthic macrofauna. Oceanogr. Mar. Biol. Annu. Rev. 33: 245-203.

Dutil, J. D., Sylvestre, E. L., Gamache, L., Larocque, R. and Guderley, H. (2007). Burst and coast use, swimming performance and metabolism of Atlantic cod (Gadus morhua) in sub-lethal hypoxic conditions. J. Fish. Biol. 71: 363-375.

Dwyer, K.S., Buren, A. and Koen-Alonso, M. (2010) Greenland halibut diet in the Northwest Atlantic from 1978 to 2003 as an indicator of ecosystem change. J. Sea Res. 64: 436-445.

Fréchet, A. (1987) Biology and Fishery of Greenland Halibut in the Gulf of St. Lawrence. NAFO SCR Doc. 87/95. 11pp. 
641 Fretwell, S.D. and Lucas, H.L. (1970) On territorial behavior and other factors influencing habitat distribution in birds. Acta Biotheo. 19: 16-36.

Fu, S-J., Brauner, C.J., Cao, Z-D., Richards, J.G., Peng, J-L., Dhillon, R., and Wang, Y. X., (2011) The effect of acclimation to hypoxia and sustained exercise on subsequent hypoxia tolerance and swimming performance in goldfish (Carassius auratus). J. Exp Biol. 214:2080-2088.

Gilbert, D., Sundby, B., Gobeil, C., Mucci, A. and Tremblay, G.H. (2005) A Seventy-TwoYear Record of Diminishing Deep-Water Oxygen in the St. Lawrence Estuary: The Northwest Atlantic Connection. Limnol Oceanogr. 50: 1654-1666.

Hastie, T. and Tibshirani, R. (1986) Generalized Additive Models. Stat Sci. 1: 297-310.

Hastie, T. and Tibshirani, R. (1990) Generalized Additive Models. London: Chapman \& Hall. 352 pp.

Hilborn, R. and Walthers, C.J. (1992) Quantitative fisheries stock assessment: Choice, dynamics and uncertainty. Chapman and Hall, New York. 570 pp.

Jørgensen, O.A. (1997a) Movement patterns of Greenland halibut, Reinhardtius hippoglossoides (Walbaum), at west Greenland, as inferred from trawl survey distribution and size data. J. Northwest Atl. Fish. Sci. 21: 23-38.

Jørgensen, O.A. (1997b) Pelagic Occurrence of Greenland Halibut, Reinhardtius hippoglossoides (Walbaum), in West Greenland Waters. J. Northwest Atl. Fish. Sci. 21: $39-50$.

Kaartvedt, S., Rostad, A. and Klevjer, T. A. (2009) Sprat Sprattus sprattus can exploit low oxygen waters for overwintering. Mar. Ecol. Prog. Ser. 390: 237-249.

Kruse, G.H., Bez, N., Booth, A., Dorn, M.W., Hills, S., Lipcius, R.N., Pelletier, D., Roy, C., Smith, S.J. and Witherell, D. (2001) Spatial processes and management of marine populations. Anchorage, Alaska: University of Alaska Sea Grant, 170pp.

Lange, A.M. (1991) Alternative Survey Indices for Predicting Availability of Longfin Squid to Seasonal Northwest Atlantic Fisheries. N. Am. J. Fish. Manage. 11: 443443.

Lavoie, D., Starr, M., Zakardjian, B. and Larouche, P. (2007) Identification of ecologically and biologically significant areas (EBSA) in the Estuary and Gulf of St. Lawrence: Primary production. Can. Sci. Adv. Sec. Res. Doc. 2007/079. 33pp.

Lesage, V., Gosselin, J.F., Lawson, J. and Hammill, O. (2007) Ecologically and Biologically Significant Areas (EBSAs) in the Estuary and Gulf of St. Lawrence - A 
marine mammal perspective. Can. Sci. Adv. Sec. Res. Doc. 2007/046. 96pp.

675

676

677

678

679

680

681

682

683

684

685

686

687

688

689

690

691

692

693

694

695

696

697

698

699

700

701

702

703

704

705

706

MacCall, A.D. (1976) Density Dependence of Catchability Coefficient in the California Pacific Sardine, Sardinops Sagax Caerulea. Purse Seine Fishery. Calif. Coop. Oceanic Fish. Invest. Rep. pp. 136-148.

MacCall, A.D. (1990) Dynamic geography of marine fish populations. Seattle: University of Washington Press. 163pp.

Maravelias, C.D. and Reid, D.G. (1997) Identifying the effects of oceanographic features and zooplankton on prespawning herring abundance using generalized additive models. Mar. Ecol. Prog. Ser. 147: 1-9.

Marshall, C.T. and Frank, K.T. (1995) Density-dependent habitat selection by juvenile haddock (Melanogrammus aeglefinus) on the southwestern Scotian Shelf. Can. J. Fish. Aquat. Sci. 52: 1007-1017.

Morin, B. and Bernier, B. (2003). Assessment of Greenland halibut (Reinhardtius hippoglossoides) in the Gulf of St. Lawrence in 2002. DFO Can. Sci. Advis. Secr. Res. Doc. 2003/08.:75 pp.

Mueter, F.J. and Norcross, B.L. (1999) Linking community structure of small demersal fishes around Kodiak Island, Alaska, to environmental variables. Mar. Ecol. Prog. Ser. 190: $37-51$.

Murawski, S.A. and Finn, J.T. (1988) Biological Bases for Mixed-Species Fisheries: Species Co-distribution in Relation to Environmental and Biotic Variables. Can. J. Fish. Aquat. Sci. 45: 1720-1735.

Myers, R.A., and Stokes, K. (1989) Density-dependent habitat utilization of groundfish and the improvement of research surveys. ICES C.M. 1989/D:15, 10pp.

Neuenfeldt, S. and Beyer, J.E. (2003) Oxygen and salinity characteristics of predator-prey distributional overlaps shown by predatory Baltic cod during spawning. J. Fish Biol. 62: $168-183$.

Ouellet, P. (2007) Contribution to the identification of ecologically and biologically significant areas (EBSA) for the Estuary and the Gulf of St. Lawrence: The fish eggs and larvae and crustacean decapods larvae layer. Can. Sci. Adv. Sec. Res. Doc. 2007/011.70pp.

Petitgas, P. (1998) Biomass-dependent dynamics of fish spatial distributions characterized by geostatistical aggregation curves. ICES J. Mar. Sci. 55: 443 -453.

Plante, S., Chabot, D. and Dutil, J.D. (1998) Hypoxia tolerance in Atlantic cod. J. Fish 
708

709

710

711

712

713

714

715

716

717

718

719

720

721

722

723

724

725

726

727

728

729

730

731

732

733

734

735

736

737

738

739

740

Plourde, S., Dodson, J.J., Runge, J.A. and Therriault, J.C. (2002) Spatial and temporal variations in copepod community structure in the lower St. Lawrence Estuary, Canada. Mar. Ecol. Prog. Ser. 230: 211-224.

Plourde, S., Joly, P., Runge, J.A., Dodson, J. and Zakardjian, B. (2003) Life cycle of Calanus hyperboreus in the lower St. Lawrence Estuary and its relationship to local environmental conditions. Mar. Ecol. Prog. Ser. 255: 219-233.

Plourde, S., Joly, P., Runge, J.A., Zakardjian, B. and Dodson, J.J. (2001) Life cycle of Calanus finmarchicus in the lower St. Lawrence Estuary: the imprint of circulation and late timing of the spring phytoplankton bloom. Can. J. Fish. Aquat. Sci. 58: 647658.

Plourde, S. and McQuinn, I.A. (2010) Ecologically and biologically significant areas in the Gulf of St. Lawrence: zooplankton and secondary production. Can. Sci. Adv. Sec. Res. Doc. 2009/104.31pp.

Plourde, S., Winkler, G., Joly, P., St-Pierre, J.F. and Starr, M. (2010) Long-term seasonal and interannual variations of krill spawning in the lower St Lawrence estuary, Canada, 1979-2009. J. Plankton Res. 33: 703-714.

Radovich, J. (1976) Catch-per-unit-of-effort: Fact, fiction or dogma. Calif. Coop. Ocean. Fish. Invest. Rep. 18: 31-33.

Rodriguez-Marin, E., Punzón, A. and Paz, J. (1995) Feeding patterns of Greenland halibut (Reinhardtius hippoglossoides) in Flemish Pass (Northwest Atlantic). NAFO Sci. Coun. Studies. 23: 43-54.

Rose, G.A. and Leggett, W.C. (1991) Effects of Biomass-Range Interactions on Catchability of Migratory Demersal Fish by Mobile Fisheries: An Example of Atlantic Cod (Gadus morhua). Can. J. Fish. Aquat. Sci. 48: 843-848.

Savenkoff, C., Valois, S., Chabot, D. and Hammill, M.O. (2009) Input Data and Parameter Estimates for Ecosystem Models of the Northern Gulf of St. Lawrence (2003-2005). Can. Tech. Rep. Fish. Aquat. Sci. 2829. 117pp.

Schaaf, W.E. (1980) An analysis of the dynamic population response of Atlantic menhaden, Brevoortia tyrannus, to an intensive fishery. Rapp. p.-v. Reun. 243pp.

Schneider, D.C., Methven, D.A. and Dalley, E.L. (1997) Geographic contraction in juvenile fish: a test with northern cod (Gadus morhua) at low abundances. Can. J. Fish. Aquat. Sci. 54: 187-199.

Shepherd, T.D. and Litvak, M.K. (2004) Density-dependent habitat selection and the ideal 
741

742

743

744

745

746

747

748

749

750

751

752

753

754

755

756

757

758

759

760

761

762

763

764

765

766

767

768

769

770

771

772

773 free distribution in marine fish spatial dynamics: considerations and cautions. Fish Fish. 5: 141-152.

Smith, S.J. (1990) Use of Statistical Models for the Estimation of Abundance from Groundfish Trawl Survey Data. Can. J. Fish. Aquat. Sci. 47: 894-903.

Swain, D.P. and Benoît, H.P. (2006) Change in habitat associations and geographic distribution of thorny skate (Amblyraja radiata) in the southern Gulf of St Lawrence: density-dependent habitat selection or response to environmental change? Fish. Oceanogr. 15: 166-182.

Swain, D.P., Chouinard, G.A., Morin, R. and Drinkwater, K.F. (1998) Seasonal variation in the habitat associations of Atlantic cod (Gadus morhua) and American plaice (Hippoglossoides platessoides) from the southern Gulf of St. Lawrence. Can. J. Fish. Aquat. Sci. 55: 2548-2561.

Swain, D.P. and Morin, R. (1996) Relationships between geographic distribution and abundance of American plaice (Hippoglossoides platessoides) in the southern Gulf of St. Lawrence. Can. J. Fish. Aquat. Sci. 53: 106-119.

Swain, D.P. and Sinclair, A.F. (1994) Fish Distribution and Catchability: What Is the Appropriate Measure of Distribution? Can. J. Fish. Aquat. Sci. 51: 1046-1054.

Swain, D.P. and Wade, E.J. (1993) Density-dependent geographic distribution of Atlantic cod (Gadus morhua) in the southern Gulf of St. Lawrence. Can. J. Fish. Aquat. Sci. 50: $725-733$.

Swartzman, G., Huang, C. and Kaluzny, S. (1992) Spatial analysis of Bering Sea groundfish survey data using generalized additive models. Can. J. Fish. Aquat. Sci. 49: $1366-1378$.

Tamdrari, H., Castonguay, M., Brêthes, J.C. and Duplisea, D. (2010) Density-independent and -dependent habitat selection of Atlantic cod (Gadus morhua) based on geostatistical aggregation curves in the northern Gulf of St Lawrence. ICES J. Mar. Sci. 67: $1676-1686$.

Winters, G.H. and Wheeler, J.P. (1985) Interaction between stock area, stock abundance, and catchability coefficient. Can. J. Fish. Aquat. Sci. 42: 989-998.

Woll, A.K. and Gundersen, A.C. (2004) Diet composition and intra-specific competition of young Greenland halibut around southern Greenland. J. Sea Res. 51: 243-249.

Wu, R.S.S. (2002) Hypoxia: from molecular responses to ecosystem responses. Mar. Pollut. Bull. 45: 35-45. 
Table 1. Correlation coefficients and significance values of the relationships between indices of distributional area $\left(\mathrm{D}_{95}, \mathrm{D}_{75}\right.$, and $\left.\mathrm{D}_{50}\right)$ of the three size classes and abundance indices. Correlations are estimated using the log transformed abundance index for the same size classes $\left(\ln \left(Y_{s, t}\right)\right)$ and that of all Greenland halibut $\left(\ln \left(Y_{t}\right)\right)$ in the Estuary and the Gulf of St. Lawrence.

\begin{tabular}{|c|c|c|c|c|c|c|c|}
\hline & & \multicolumn{2}{|c|}{$\mathrm{D}_{95}$} & \multicolumn{2}{|c|}{$\mathrm{D}_{75}$} & \multicolumn{2}{|c|}{$\mathrm{D}_{50}$} \\
\hline & & $Y_{s, t}$ & $Y_{t}$ & $Y_{S, t}$ & $Y_{t}$ & $Y_{s, t}$ & $Y_{t}$ \\
\hline \multirow[t]{2}{*}{$15-31 \mathrm{~cm}$} & $r^{2}$ & 0.302 & 0.359 & 0.304 & 0.389 & 0.320 & 0.380 \\
\hline & $p$ & 0.010 & 0.004 & 0.010 & 0.003 & 0.007 & 0.003 \\
\hline \multirow[t]{2}{*}{$32-43 \mathrm{~cm}$} & $r^{2}$ & 0.181 & 0.254 & 0.094 & 0.217 & 0.050 & 0.185 \\
\hline & $p$ & 0.054 & 0.020 & 0.177 & 0.033 & 0.331 & 0.052 \\
\hline \multirow[t]{2}{*}{$\geq 44 \mathrm{~cm}$} & $r^{2}$ & 0.622 & 0.372 & 0.262 & 0.154 & 0.012 & 0.017 \\
\hline & $p$ & $<0.0001$ & 0.003 & 0.018 & 0.079 & 0.643 & 0.568 \\
\hline
\end{tabular}


Table 2. Distributional area $\left(\mathrm{km}^{2}\right)$ occupied by $95 \%$ (D95), 75\% (D75), and 50\% (D50) of the Greenland halibut from the three size classes during periods of low and high abundance. Mean values with standard deviations are presented.

\begin{tabular}{lllll}
\hline Abundance & Area & $15-31 \mathrm{~cm}$ & $32-43 \mathrm{~cm}$ & $\geq 44 \mathrm{~cm}$ \\
\hline Low & D95 & $31836 \pm 9220$ & $44384 \pm 11342$ & $42908 \pm 9401$ \\
& D75 & $14441 \pm 5527$ & $24570 \pm 5223$ & $24380 \pm 4541$ \\
& D50 & $6567 \pm 2409$ & $12402 \pm 5114$ & $12057 \pm 2645$ \\
High & D95 & $44383 \pm 11342$ & $51510 \pm 4372$ & $53377 \pm 1708$ \\
& D75 & $21382 \pm 3466$ & $26291 \pm 2283$ & $27245 \pm 1893$ \\
& D50 & $10741 \pm 2438$ & $13486 \pm 3737$ & $12111 \pm 2645$ \\
\hline
\end{tabular}


Table 3. Results from the generalized additive models (GAM) for the three size classes of Greenland halibut during the 1990-2010 period. The total deviance (\%) explained by the final model for each size class, the estimated degrees of freedom (EDF), F value, and probability level of significance (p) are given for each variable or interaction term.

\begin{tabular}{lcccc}
\hline & EDF & F & p & Deviance (\%) \\
\hline $15-31 \mathrm{~cm}$ & & & & 76.6 \\
s(longitude, latitude) & 28.44 & 148.44 & $<0.00001$ & \\
s(depth) & 8.64 & 51.83 & $<0.00001$ & \\
s(temperature) & 7.81 & 5.40 & $<0.00001$ & \\
s( $Y_{s, t}$-mean annual catch tow $\left.{ }^{-1}\right)$ & 7.88 & 113.9 & $<0.00001$ & \\
$32-43$ cm & & & & 73.8 \\
s(longitude, latitude) & 28.47 & 108.17 & $<0.00001$ & \\
s(depth) & 8.00 & 72.22 & $<0.00001$ & \\
s(temperature) & 8.63 & 7.11 & $<0.00001$ & \\
s( $Y_{s, t}-$ mean annual catch tow $\left.{ }^{-1}\right)$ & 7.70 & 134.90 & $<0.00001$ & \\
$\geq 44$ cm & & & & \\
s(longitude, latitude) & 27.79 & 40.25 & $<0.00001$ & \\
s(depth) & 8.20 & 42.92 & $<0.00001$ & \\
s(temperature) & 8.30 & 3.64 & $<0.0002$ & \\
s( $Y_{s, t}-$ mean annual catch tow $\left.{ }^{-1}\right)$ & 2.89 & 176.97 & $<0.00001$ & \\
\hline
\end{tabular}


Table 4. Results from the generalized additive models (GAM) for the three size classes of Greenland halibut during the 2004-2010 period with DO concentration included as an additional environmental variable. The total deviance (\%) explained by the final model for each size class, the estimated degrees of freedom (EDF), F value, and probability level of significance (p) are given for each variable or interaction term.

\begin{tabular}{|c|c|c|c|c|}
\hline & $\mathrm{EDF}$ & $\mathrm{F}$ & $\mathrm{P}$ & Deviance $(\%)$ \\
\hline $15-31 \mathrm{~cm}$ & & & & 82.9 \\
\hline s(longitude, latitude) & 23.26 & 13.62 & $<0.00001$ & \\
\hline $\mathrm{s}($ depth$)$ & 8.65 & 13.84 & $<0.00001$ & \\
\hline$s($ temperature $)$ & 5.83 & 4.05 & 0.0002 & \\
\hline s(oxygen) & 6.66 & 23.31 & $<0.00001$ & \\
\hline $\bar{Y}_{s, t}$ & & & $<0.00001$ & \\
\hline $32-43 \mathrm{~cm}$ & & & & 85.8 \\
\hline s(longitude, latitude) & 20.07 & 11.93 & $<0.00001$ & \\
\hline s(depth) & 6.39 & 50.85 & $<0.00001$ & \\
\hline s(temperature) & 6.25 & 2.94 & 0.0039 & \\
\hline s(oxygen) & 6.99 & 15.38 & $<0.00001$ & \\
\hline $\bar{Y}_{s, t}$ & & & $<0.00001$ & \\
\hline$\geq 44 \mathrm{~cm}$ & & & & 72.5 \\
\hline s(longitude, latitude) & 25.79 & 6.87 & $<0.00001$ & \\
\hline $\mathrm{s}($ depth $)$ & 7.09 & 25.55 & $<0.00001$ & \\
\hline $\mathrm{s}($ temperature $)$ & 1.00 & 0.46 & 0.499 & \\
\hline s(oxygen) & 5.88 & 9.10 & $<0.00001$ & \\
\hline $\bar{Y}_{s, t}$ & & & 0.0019 & \\
\hline
\end{tabular}


Table 5. Relative contribution of the different variables to the total deviance (\%) explained by the final model for each size class of Greenland halibut during the 19902010 period. The relative contribution made by the identified variables or variable interaction is determined by the change in total deviance explained by the full model and the model with the different variables dropped.

\begin{tabular}{|c|c|c|c|}
\hline Size class & Variable & $\begin{array}{l}\text { Deviance } \\
\text { explained }(\%) \\
\text { by the model }\end{array}$ & $\begin{array}{l}\% \text { change in } \\
\text { deviance from } \\
\text { full model }\end{array}$ \\
\hline \multirow[t]{5}{*}{$15-31 \mathrm{~cm}$} & Longitude, latitude & 45.9 & 30.7 \\
\hline & Depth & 73.2 & 3.4 \\
\hline & Temperature & 74.6 & 2.0 \\
\hline & Depth and temperature & 62.3 & 14.3 \\
\hline & Abundance $\left(\bar{Y}_{s, t}\right)$ & 69.6 & 7.0 \\
\hline \multirow[t]{5}{*}{$32-43 \mathrm{~cm}$} & Longitude, latitude & 48.5 & 25.3 \\
\hline & Depth & 68.6 & 5.2 \\
\hline & Temperature & 73.5 & 0.3 \\
\hline & Depth and temperature & 56.2 & 17.6 \\
\hline & Abundance $\left(\bar{Y}_{s, t}\right)$ & 64.6 & 9.2 \\
\hline \multirow[t]{5}{*}{$\geq 44 \mathrm{~cm}$} & Longitude, latitude & 43.8 & 14.8 \\
\hline & Depth & 53.7 & 4.9 \\
\hline & Temperature & 58.3 & 0.3 \\
\hline & Depth and temperature & 42.4 & 16.2 \\
\hline & Abundance $\left(\bar{Y}_{s, t}\right)$ & 50.9 & 7.7 \\
\hline
\end{tabular}


Table 6. Relative contribution of the different variables to the total deviance (\%) explained by the final model for each size class of Greenland halibut during the 20042010 period with DO concentration included as an additional environmental variable. The relative contribution made by the identified variables or variable interaction is determined by the change in total deviance explained by the full model and the model with the different variables dropped.

\begin{tabular}{|c|c|c|c|}
\hline Size class & Variable & $\begin{array}{l}\text { Deviance } \\
\text { explained }(\%) \\
\text { by the model }\end{array}$ & $\begin{array}{l}\% \text { change in } \\
\text { deviance from } \\
\text { full model }\end{array}$ \\
\hline \multirow[t]{7}{*}{$15-31 \mathrm{~cm}$} & Longitude, latitude & 74.6 & 8.3 \\
\hline & Oxygen & 79.4 & 3.5 \\
\hline & Depth & 80.0 & 2.9 \\
\hline & Temperature & 81.7 & 1.2 \\
\hline & Abundance $\left(\bar{Y}_{s, t}\right)$ & 82.3 & 0.6 \\
\hline & Longitude, latitude and oxygen & 45.8 & 37.1 \\
\hline & Oxygen and depth and temperature & 61.0 & 21.9 \\
\hline \multirow[t]{7}{*}{$32-43 \mathrm{~cm}$} & Longitude, latitude & 79.7 & 6.1 \\
\hline & Oxygen & 84.1 & 1.7 \\
\hline & Depth & 79.1 & 6.7 \\
\hline & Temperature & 85.3 & 0.5 \\
\hline & Abundance $\left(\bar{Y}_{s, t}\right)$ & 85.3 & 0.5 \\
\hline & Longitude, latitude and oxygen & 58.8 & 27.0 \\
\hline & Oxygen and depth and temperature & 55.1 & 30.7 \\
\hline \multirow[t]{6}{*}{$\geq 44 \mathrm{~cm}$} & Longitude, latitude & 65.8 & 6.9 \\
\hline & Oxygen & 70.0 & 2.7 \\
\hline & Depth & 65.7 & 7.0 \\
\hline & Abundance $\left(\bar{Y}_{s, t}\right)$ & 72.4 & 0.3 \\
\hline & Longitude, latitude and oxygen & 55.5 & 17.2 \\
\hline & Oxygen and depth & 42.4 & 30.3 \\
\hline
\end{tabular}




\section{$1 \quad$ List of figures}

2 Fig 1. Annual variations in the abundance (mean catches in numbers per standard tow) of 3 Greenland halibut (Reinhardtius hippoglossoides) in the Estuary and Gulf of St. Lawrence 4 over the DFO and sentinel fishery surveys time series (1990-2010). Abundance indices for 5 juveniles of both sexes $(15-31 \mathrm{~cm})(\mathrm{a})$, immature sub adult females and adult males (32-43

$6 \mathrm{~cm})(\mathrm{b})$ and large adults of both sexes $(\geq 44 \mathrm{~cm})(\mathrm{c})$ are presented.

7 Fig 2. Variations in spatial distribution of Greenland halibut in the Estuary and Gulf of St. 8 Lawrence during periods of low (a, c, e) and high (b, $d, f)$ abundance for fish sizes of 15-31 $9 \mathrm{~cm}(\mathrm{a}, \mathrm{b}), 32-43 \mathrm{~cm}(\mathrm{c}, \mathrm{d})$, and $\geq 44 \mathrm{~cm} \mathrm{(e,} \mathrm{f).} \mathrm{Abundance} \mathrm{is} \mathrm{expressed} \mathrm{as} \mathrm{the} \log$ of catch 10 numbers per standard tow for the following intervals: $\square: 0.4-0.8, \square: 0.8-1.2, \square: 1.2-1.6, \square$ : $11 \quad 1.6-2.0, \square:>2.0$.

12 Fig 3. Relationships between indices of distributional area occupied by $95 \%$, $75 \%$, and $1350 \%$ of the fish and relative abundance $\left(\mathrm{Y}_{\mathrm{t}}\right.$; mean number of fish per tow) for the different 14 size classes of Greenland halibut for the period between 1990 and 2010.

15 Fig 4. Relationship between index of habitat quality and rate of local density change ( $\beta$ ) for 16 juveniles (a), immature sub adult females and adult males (b) and large adults ( $\geq 44 \mathrm{~cm})$ (c). 17 Index of habitat quality is determined by the mean catch rate during periods of low 18 abundance and rate of local density change from eq. 6 in the text.

19 Fig 5. Results of GAM regressions of the effects of spatial location (latitude and longitude), 20 environmental variables (depth and temperature) and mean annual abundance of Greenland 
21 halibut on the catches (number of fish per standard tow) of juvenile fish $(15-31 \mathrm{~cm})$ in the

22 Estuary and Gulf of St. Lawrence for the 1990-2010 period. Contour lines for

23 longitude:latitude interaction indicate different levels of catches (fitted values adjusted to

24 an average of 0 ). Solid line indicates the fitted relationships for single covariates and the

25 dotted lines the $95 \%$ confidence intervals. The y-axis for individual covariates is scaled to

26 an average of 0 and the rugplots on the $\mathrm{x}$-axis indicate the number of observations.

27 Fig 6. Results of GAM regressions of the effects of spatial location (latitude and longitude),

28 environmental variables (depth and temperature) and mean annual abundance of Greenland

29 halibut on the catches (number of fish per standard tow) of fish in the $32-43 \mathrm{~cm}$ size range

30 in the Estuary and Gulf of St. Lawrence for the 1990-2010 period. Contour lines for

31 longitude:latitude interaction indicate different levels of catches (fitted values adjusted to

32 an average of 0 ). Solid line indicates the fitted relationships for single covariates and the

33 dotted lines the $95 \%$ confidence intervals. The y-axis for individual covariates is scaled to

34 an average of 0 and the rugplots on the $\mathrm{x}$-axis indicate the number of observations.

35 Fig 7. Results of GAM regressions of the effects of spatial location (latitude and longitude),

36 environmental variables (depth and temperature) and mean annual abundance of Greenland

37 halibut on the catches (number of fish per standard tow) of large fish $(\geq 44 \mathrm{~cm})$ in the

38 Estuary and Gulf of St. Lawrence for the 1990-2010 period. Contour lines for

39 longitude:latitude interaction indicate different levels of catches (fitted values adjusted to

40 an average of 0 ). Solid line indicates the fitted relationships for single covariates and the

41 dotted lines the $95 \%$ confidence intervals. The y-axis for individual covariates is scaled to 
42 an average of 0 and the rugplots on the $\mathrm{x}$-axis indicate the number of observations.

43 Fig 8. Results of GAM regressions of the effects of geographic location (latitude and

44 longitude) and environmental variables (depth, temperature and dissolved oxygen) on the 45 catches of juvenile Greenland halibut $(15-31 \mathrm{~cm})$ in the Estuary and Gulf of St. Lawrence 46 during the 2004-2010 period. Contour lines for longitude:latitude interaction indicate 47 different levels of catches (fitted values adjusted to an average of 0 ). Solid line indicates the 48 fitted relationships for single covariates and the dotted lines the $95 \%$ confidence intervals.

49 The $\mathrm{y}$-axis for individual covariates is scaled to an average of 0 and the rugplots on the $\mathrm{x}$ 50 axis indicate the number of observations.

51 Fig 9. Results of GAM regressions of the effects of geographic location (latitude and 52 longitude) and environmental variables (depth, temperature and dissolved oxygen) on the 53 catches of fish in the 32-43 cm Greenland halibut in the Estuary and Gulf of St. Lawrence 54 during the 2004-2010 period. Contour lines for longitude:latitude interaction indicate 55 different levels of catches (fitted values adjusted to an average of 0). Solid line indicates the 56 fitted relationships for single covariates and the dotted lines the $95 \%$ confidence intervals. 57 The $\mathrm{y}$-axis for individual covariates is scaled to an average of 0 and the rugplots on the $\mathrm{x}$ 58 axis indicate the number of observations.

59 Fig 10. Results of GAM regressions of the effects of geographic location (latitude and 60 longitude) and environmental variables (depth, temperature and dissolved oxygen) on the 61 catches of large Greenalnd halibut $(\geq 44 \mathrm{~cm})$ in the Estuary and Gulf of St. Lawrence 62 during the 2004-2010 period. Contour lines for longitude:latitude interaction indicate 
63 different levels of catches (fitted values adjusted to an average of 0). Solid line indicates the

64 fitted relationships for single covariates and the dotted lines the $95 \%$ confidence intervals.

65 The $\mathrm{y}$-axis for individual covariates is scaled to an average of 0 and the rugplots on the $\mathrm{x}-$ 66 axis indicate the number of observations.

67 Fig 11. Contour plot of GAM predictions of dissolved oxygen levels ( $\mu \mathrm{mol} / \mathrm{L})$ from 2004 68 to 2010 in the Estuary and Gulf of St. Lawrence in relation to longitude and depth.

69 

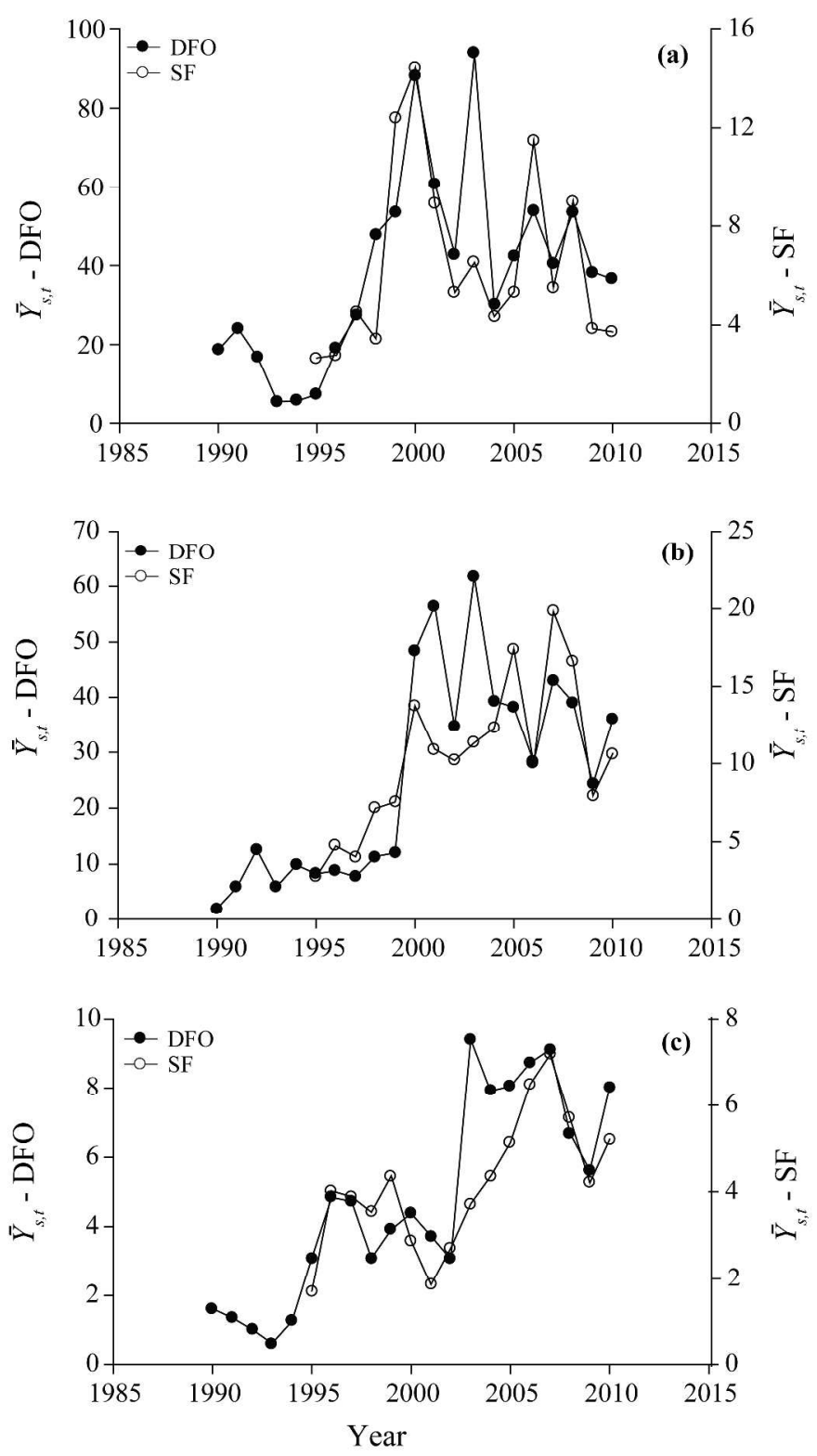

$296 \times 530 \mathrm{~mm}(300 \times 300$ DPI $)$ 

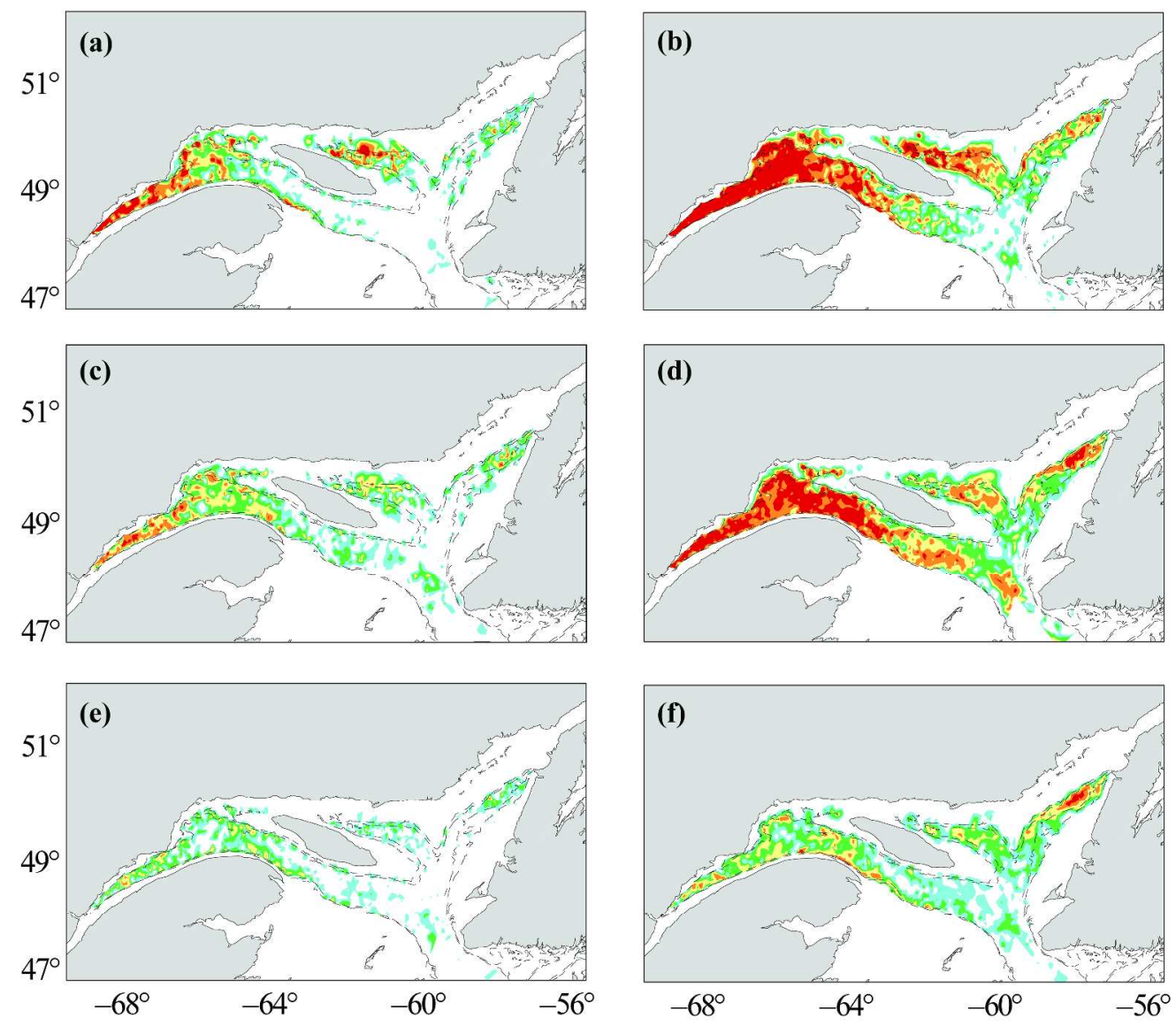

$310 \times 273 \mathrm{~mm}(300 \times 300 \mathrm{DPI})$ 


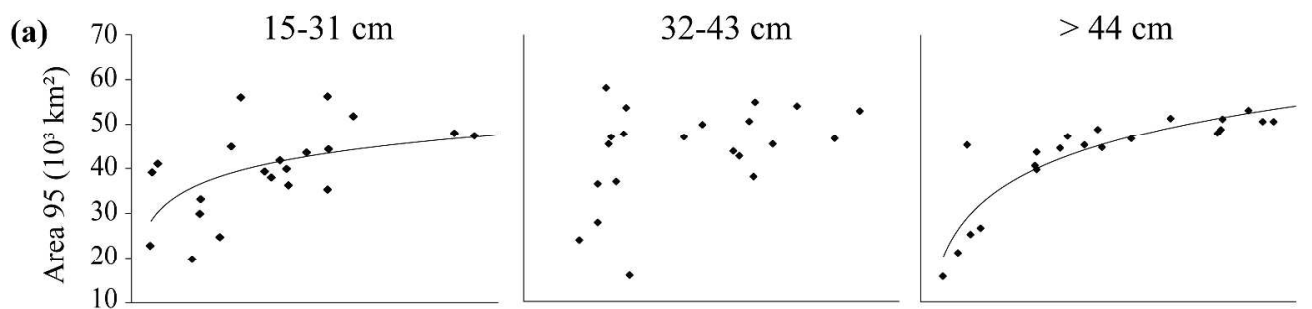

(b)

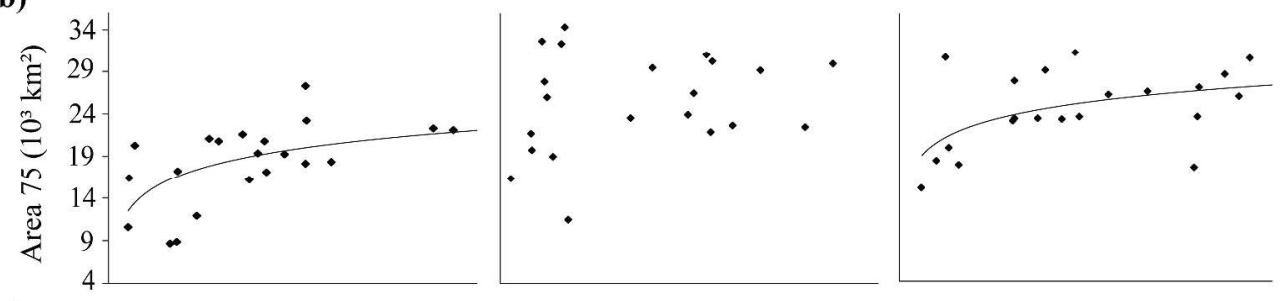

(c)

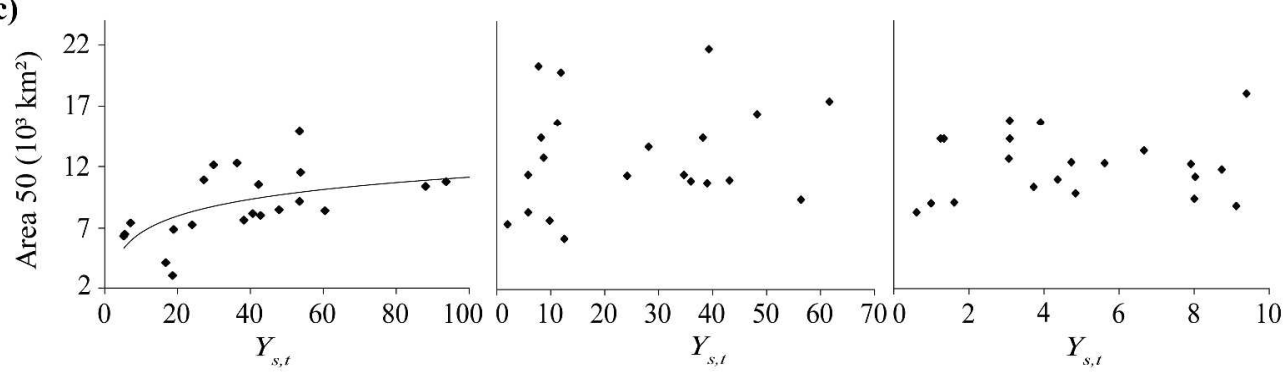

$477 \times 366 \mathrm{~mm}(300 \times 300$ DPI $)$ 

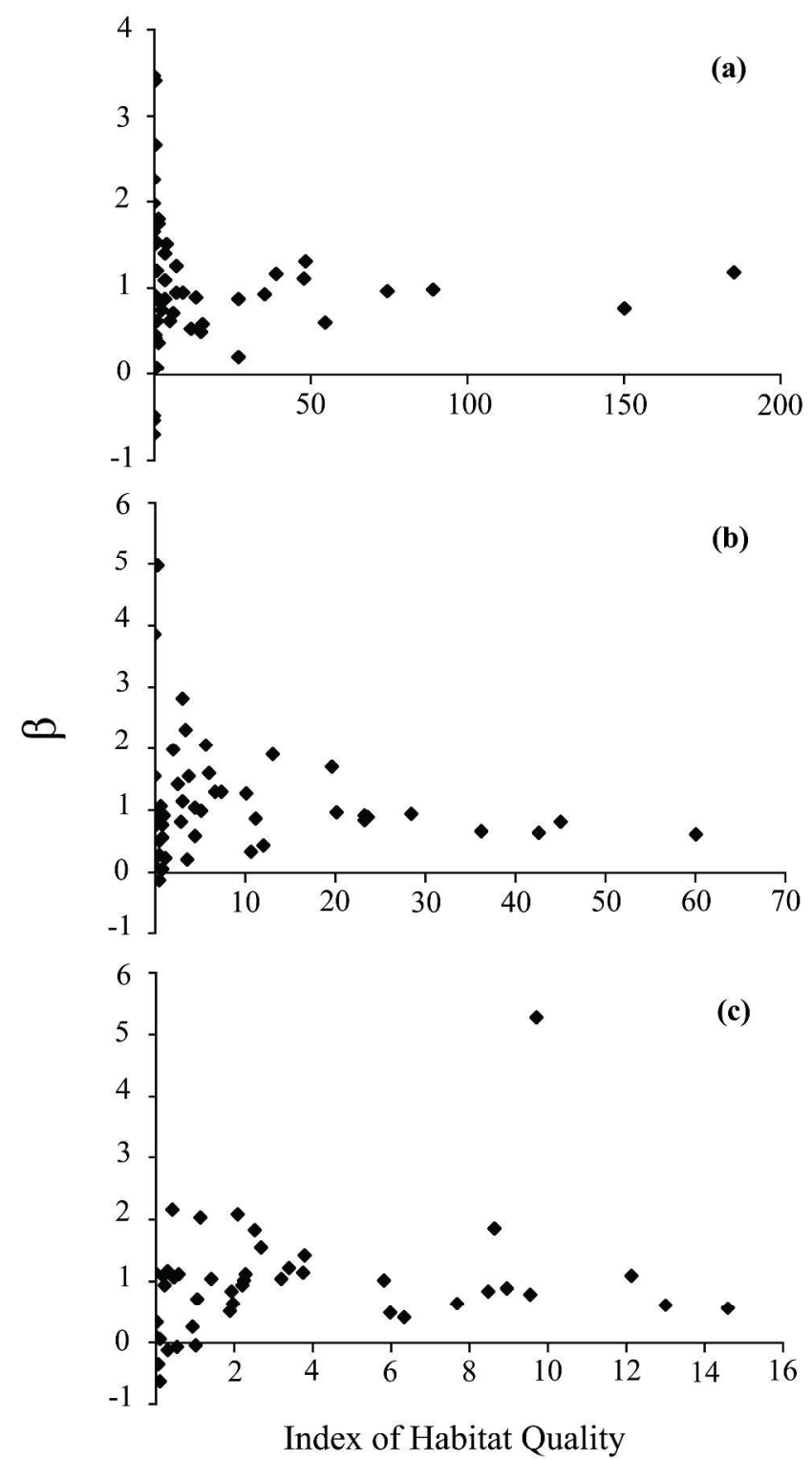

$258 \times 483 \mathrm{~mm}(300 \times 300$ DPI $)$ 

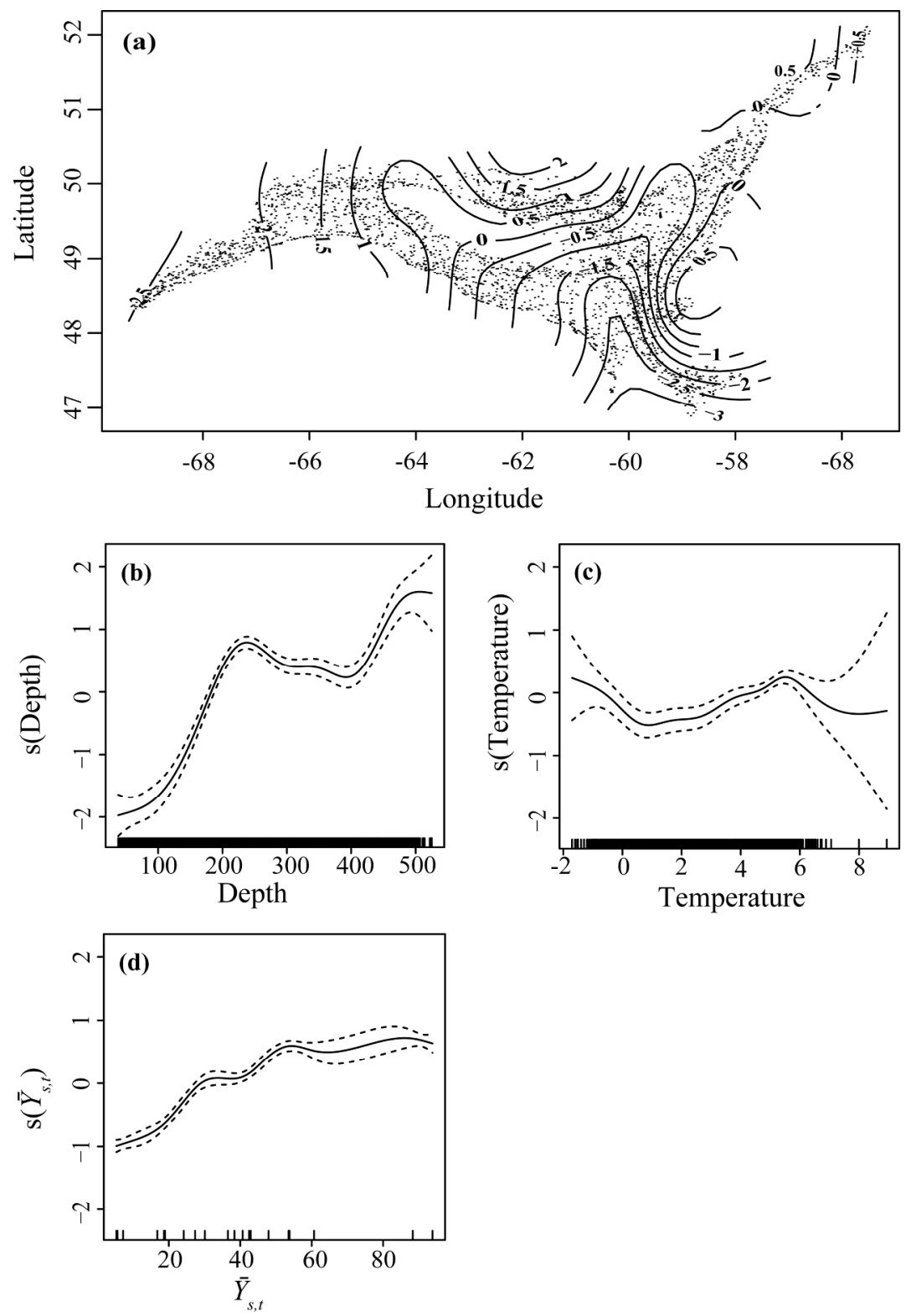

$174 \times 256 \mathrm{~mm}(300 \times 300 \mathrm{DPI})$ 

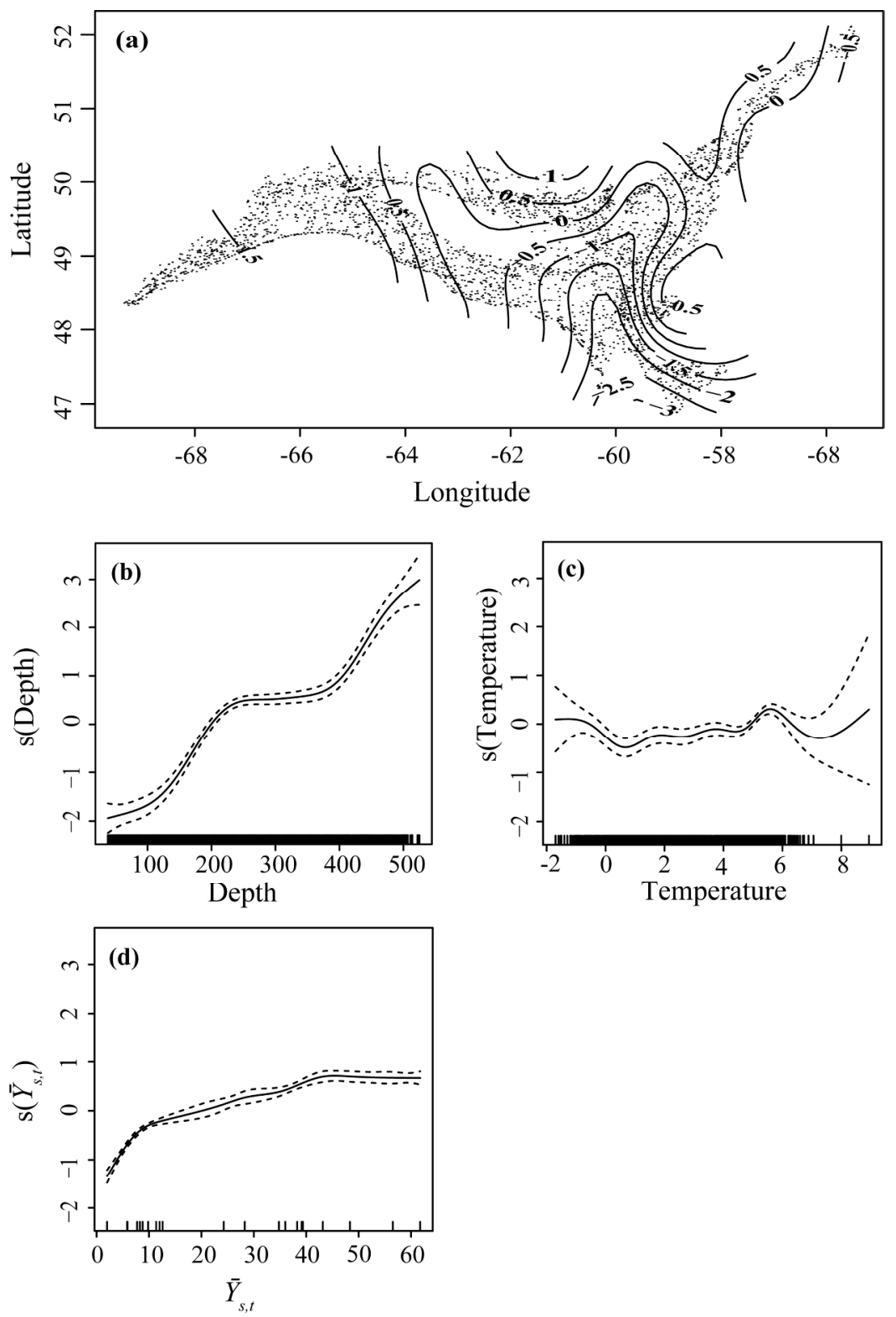

$173 \times 258 \mathrm{~mm}(300 \times 300 \mathrm{DPI})$ 

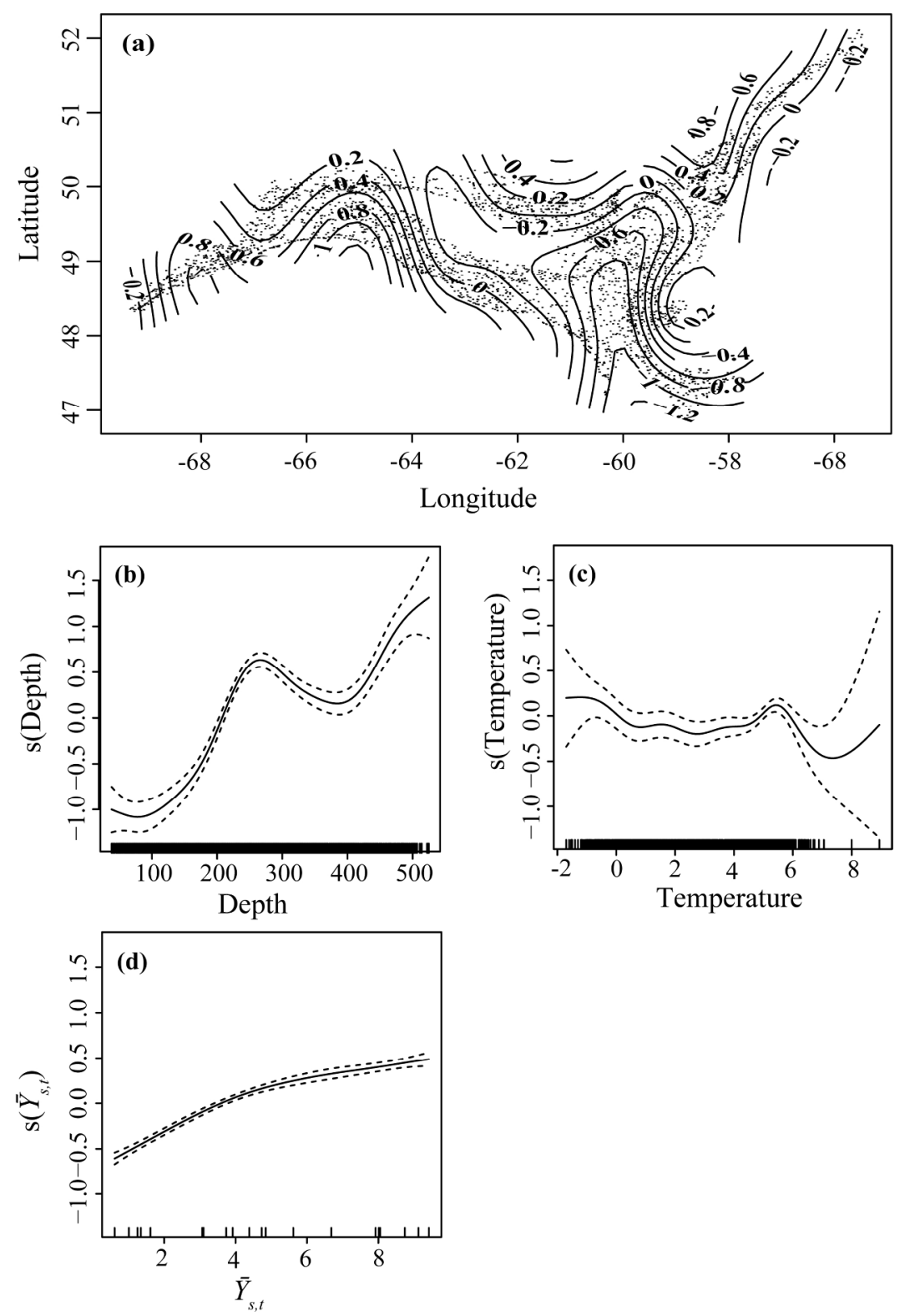

$172 \times 256 \mathrm{~mm}(300 \times 300 \mathrm{DPI})$ 

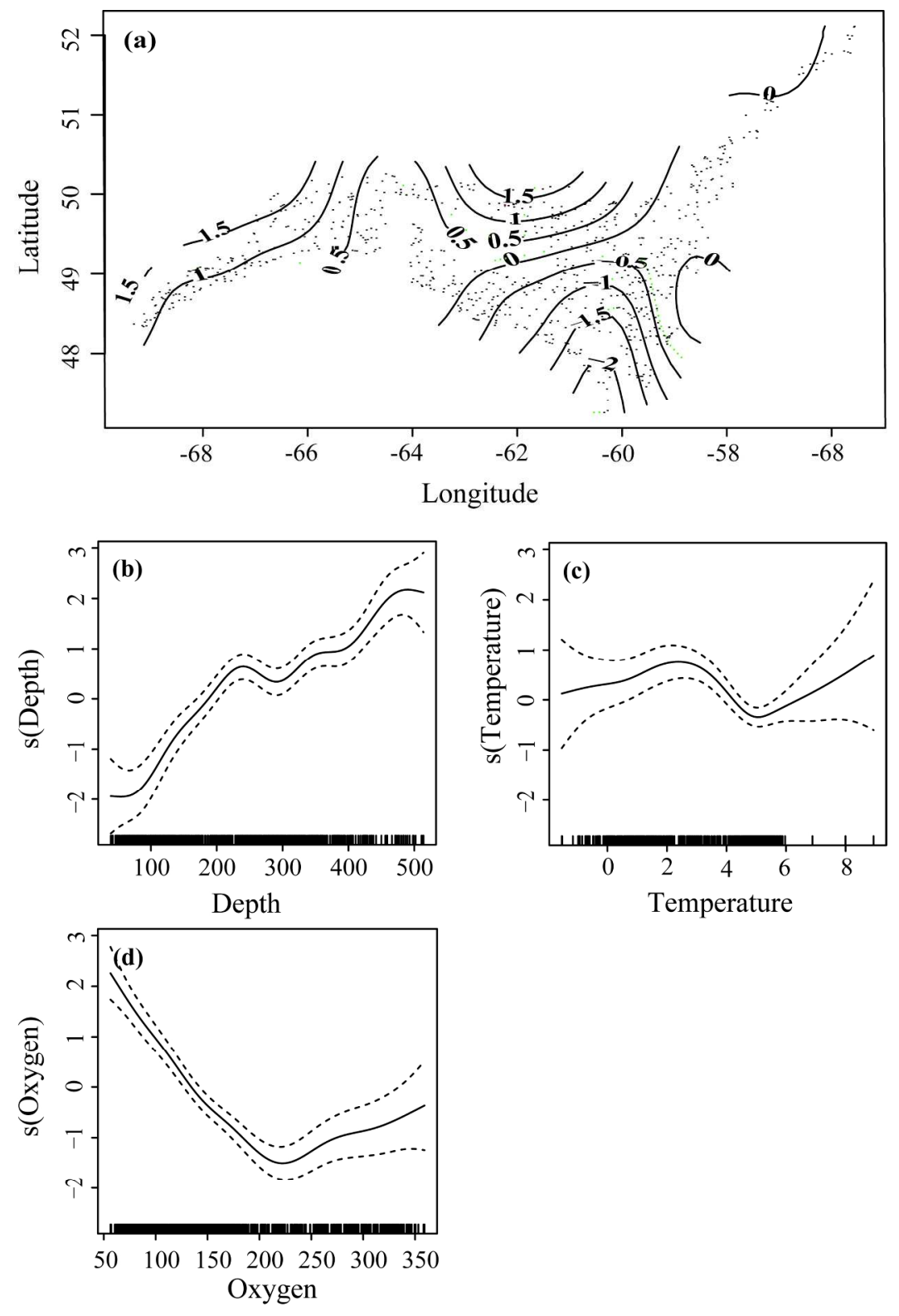

$172 \times 256 \mathrm{~mm}(300 \times 300 \mathrm{DPI})$ 

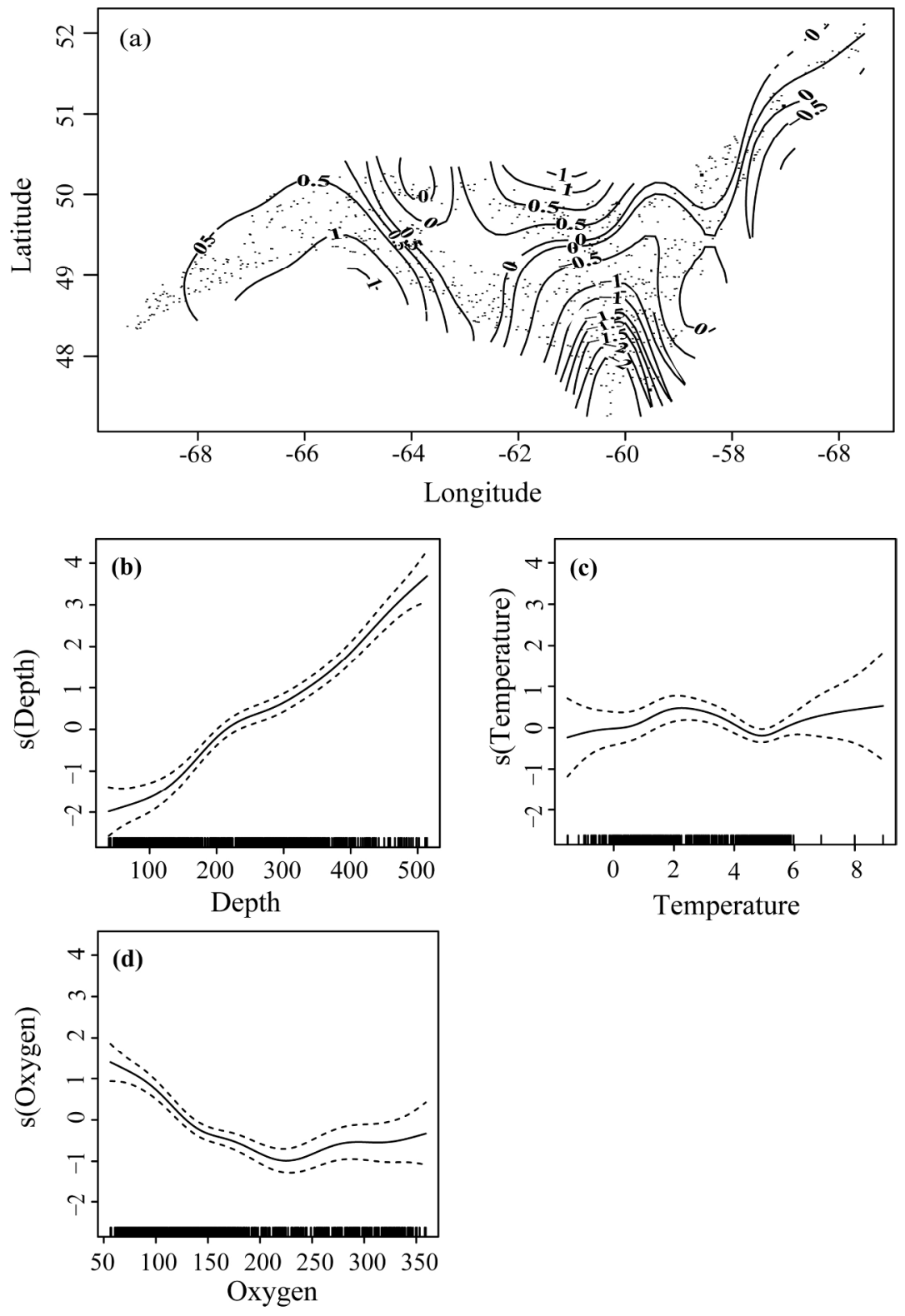

$174 \times 254 \mathrm{~mm}(300 \times 300$ DPI $)$ 

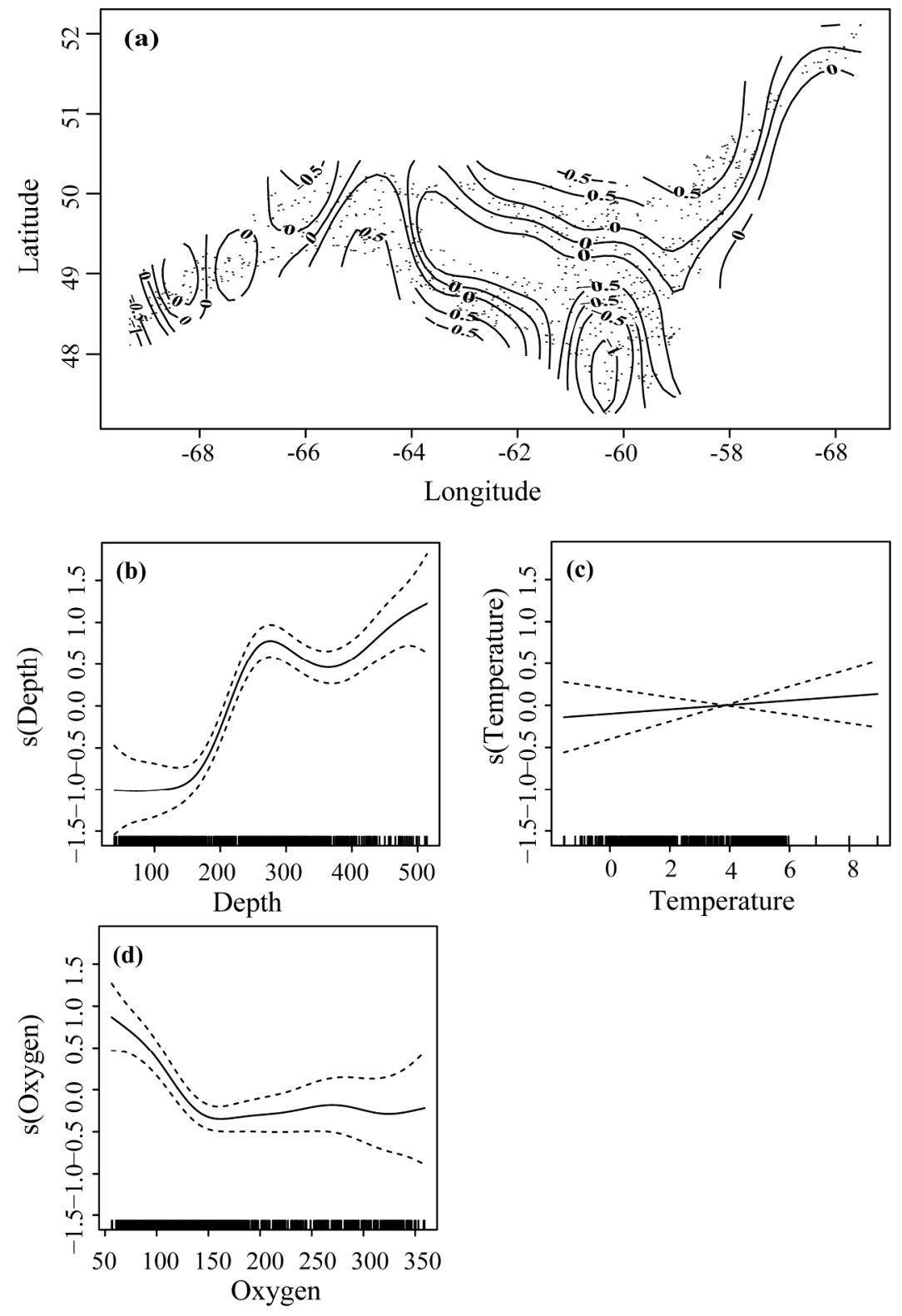

$173 \times 256 \mathrm{~mm}(300 \times 300$ DPI $)$ 


\section{Page 55 of 55}

Fisheries Oceanography

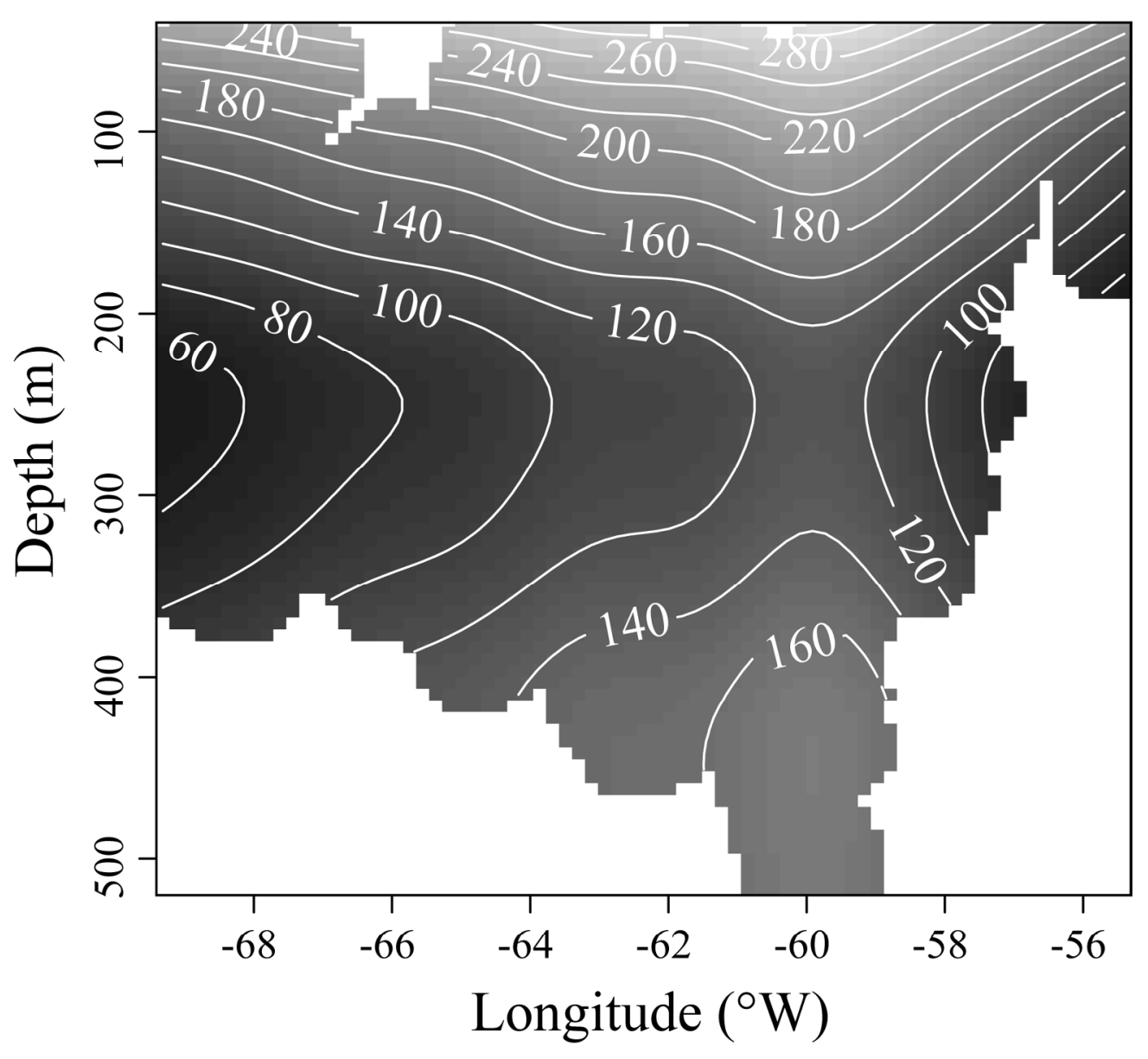

$169 \times 157 \mathrm{~mm}(300 \times 300$ DPI $)$ 